Wang, Z. X., Wang, Y. Q., Zhang, Y., Gardner, L., and Ouyang, Y. W. (2019). Experimental investigation and design of extruded aluminium alloy T-stubs connected by swage-locking pins. Engineering Structures, 200. https://doi.org/10.1016/j.engstruct.2019.109675

\title{
Experimental investigation and design of extruded aluminium alloy $T$ - stubs connected by swage-locking pins
}

Zhongxing Wang ${ }^{\mathrm{a}, \mathrm{b}}$, Yuanqing Wang, Ying Zhang ${ }^{\mathrm{a}}$, Leroy Gardner ${ }^{\mathrm{b}^{*}}$ and Yuanwen Ouyang ${ }^{\mathrm{c}}$

${ }^{a}$ Department of Civil Engineering, Tsinghua University, Beijing 10084, PR China

${ }^{b}$ Department of Civil and Environmental Engineering, South Kensington Campus, Imperial College London, London SW7 2AZ, UK

${ }^{c}$ Shanghai Tongzheng Aluminium Engineering Co., Ltd., Shanghai 200030, PR China

*Corresponding author, Email: Leroy.gardner@imperial.ac.uk

\begin{abstract}
The structural behaviour and design of extruded aluminium alloy T-stubs connected by swage-locking pins under monotonic loading are investigated in this study. Thirty experiments were performed and the test set-up, testing procedure and experimental results, including failure modes, ultimate load-carrying capacity, deformation capacity and load-displacement response, are reported. Component tests were also carried out on the swage-locking pins to assess their load-carrying capacities under pure tension, pure shear and combined tension and shear; these tests were complemented by tensile coupon tests on the pin and T-stub plate material. Resistance functions to predict the capacity of the swage-locking pins were developed and assessed against the test results. The EN 1999-11 (EC9) design rules for predicting the resistance of extruded aluminium alloy T-stubs were also evaluated and found to be safe-sided, but rather conservative relative to the experimental results. Improved resistance predictions were achieved through application of the continuous strength method (CSM).
\end{abstract}


Keywords: Aluminium alloy; T-stub joints; Experiments; Continuous strength method (CSM); Swage-locking pin; Testing.

\section{Introduction}

Aluminium alloys have been widely used in many thousands of space structures as well as different types of bridges [1] due to their sound structural characteristics combined with good corrosion resistance, high strength-to-weight ratio and aesthetic appearance. Although research into the behaviour of aluminium alloy beams and columns dates back to early last century, research into aluminium alloy beam-to-column joints is far more limited. De Matteis and Brando [2] highlighted the virtues of testing T-stubs as an efficient and cost-effective means of evaluating the key components affecting the performance characteristics of beam-to-column joints. Following this, designers or researchers can apply the well-known 'component method' [3] set out in EN 1993-1-8 [4] to analyse the flexural response of a given joint. An equivalent T-stub can represent the behaviour of angle cleats in bending, end plates in bending and column flanges in bending, as shown in Fig. 19, through the component method [5]. Research on T-stubs is therefore an essential first step to studying the behaviour of aluminium alloy beam-to-column joints and to applying them in practical engineering applications.

Owing to the nonlinearity, strain hardening behaviour and limited ductility of the material, the structural behaviour of aluminium alloy T-stubs may differ significantly from that of steel T-stubs, which have been widely studied [6-11]. De Matteis and his coworkers conducted 26 tests on welded aluminium alloy T-stub joints connected by bolts under both monotonic loading [12] and cyclic loading [13] and carried out corresponding numerical [14] and parametric analyses [15]. Xu et al. [16] performed a finite element 
study into the behaviour of bolted aluminium alloy T-stubs to investigate the failure modes, ultimate load-bearing capacity and effective length of flanges. Building on this previous research, the purpose of the present paper is to provide test data on extruded aluminium alloy T-stubs connected by swage-locking pins, which have not been studied to date, under tensile force and to utilise the results to evaluate the accuracy of current design methods.

In total, thirty extruded aluminium alloy $\mathrm{T}$-stub joints were tested under monotonic loading, with the key varied parameters being the distance between the fasteners and the T-stub web, the flange thickness, the swage-locking pin collar type and the diameter and layout of the fasteners. All the T-stub joints were connected by swage-locking pins which can be very rapidly fastened using a specialized tool and are resistant to loosening and vibration. The load-carrying capacity, deformation capacity and failure modes obtained from the T-stub joint tests are presented and analysed. Finally, the test results are used to evaluate existing design methods and to assess the reliability of a proposed new design approach. Inclusion of provisions for T-stubs and swage-locking pins are anticipated in the next revision of the Chinese code for design of aluminium structures GB 50429 [17].

\section{Experimental programme}

An experimental programme comprising tests on T-stubs and their constituent components, i.e. plate material and swage-locking pins, is described in this section. The experimental results are reported in Section 3.

\subsection{Test specimens}

Thirty extruded aluminium alloy T-stubs connected by swage-locking pins were tested to study their structural behaviour under tensile loading. The configuration of the test specimens is shown in Fig. 20, where TSS refers to T-stub specimens with a single row 
and a single column of pins, TSD refers to T-stub specimens with a single row and double columns of pins, TDS refers to T-stub specimens with double rows and a single column of pins and TDD refers to T-stub specimens with double rows and double columns of pins. The specimens were tested in pairs, back-to-back, rather than as single T-stubs assembled against a rigid support, to avoid premature shear failure of the fasteners [5]. The T-stubs were connected together by swage-locking pins, which are a new type of fastener, resistant to loosening and vibration. The pins were made of stainless steel, while the collars were made of either aluminium alloy or stainless steel, neither of which lead to electrochemical corrosion with the aluminium alloy T-stubs. The stainless steel-collar pins have a larger load-carrying capacity than the aluminium alloy-collar pins, but at a higher cost. In the tests performed herein, two swage-locking pin diameters were considered $-9.66 \mathrm{~mm}$ and $12.70 \mathrm{~mm}$. Since the $9.66 \mathrm{~mm}$ pins are the most widely available, these were used in the majority of the experiments; a limited number of tests using $12.70 \mathrm{~mm}$ pins with aluminium alloy collars were performed. The connecting process is shown in Fig. 21. The installation tool is a hydraulic rivet gun, which preloads the swage-locking pin and plastically deforms the collar in order to tightly grip the thread. The preload provides an increase in axial stiffness to the T-stubs [6].

The measured dimensions of all the specimens are presented in Table 7, in which $d_{\text {pin }}$ is the diameter of the swage-locking pins, $F_{\mathrm{p}, \mathrm{C}}$ is the preload in the fasteners (i.e. the swage-locking pins) measured by a specially devised load cell and other symbols are as defined in Fig. 20. The nominal value of $d_{\mathrm{p}}$ and $d_{\mathrm{e}}$ for the TSD and TDD specimens was $30 \mathrm{~mm}$ and $25 \mathrm{~mm}$ respectively, while the nominal value of $t_{\mathrm{w}}$ was $8 \mathrm{~mm}$ for all specimens.

The specimens are labelled such that the key parameters including the T-stub type (TSS, TSD, TDS, or TDD), the pin collar material (aluminium alloy (A) or stainless steel (S)), the flange thickness $(8 \mathrm{~mm}, 10 \mathrm{~mm}$ or $12 \mathrm{~mm})$ and the distance between the pin and web 
(from $20 \mathrm{~mm}$ to $50 \mathrm{~mm}$ ) can be identified from the label. For example, the label TSDA-820 indicates a TSD-type T-stub, with aluminium alloy pin collars (if the fourth letter is "S", it indicates that the material of the pin collar is stainless steel), a nominal flange thickness of $8 \mathrm{~mm}$ and a nominal distance between the pins and the web of $20 \mathrm{~mm}$. However, for the specimens with double rows of pins (i.e. the TDS- and TDD- type specimens), the last group of number indicates the fastener pitch $e_{2}$, which is defined in Fig. 2; for example, the label TDDA-10-30-25 indicates a TDD-type specimen with aluminium alloy pin collars, a flange thickness of $10 \mathrm{~mm}$, a distance between the pins and the web of $30 \mathrm{~mm}$ and a fastener pitch of $25 \mathrm{~mm}$.

\subsection{Tests on swage-locking pins}

Prior to the testing of the T-stubs, 42 experiments on swage-locking pins under pure tension, pure shear and combined tension and shear were conducted. As well as the familiar failure modes associated with ordinary bolts in tension and shear, swage-locking pins also exhibit an additional failure mode termed collar pull-out.

A special fixture [18] was devised to load the swage-locking pins with different combinations of tension and shear force, as shown in Fig. 22 (a). By changing the position of the loading bar, the pins could be loaded at a variety of angles, at 15 degree intervals. The tests were performed using a $300 \mathrm{kN}$ hydraulic testing machine under load control and the test setup is illustrated in Fig. 22 (b). The deformation was measured using a video gauge which is detailed in Section 2.4. The measurement points were marked onto the front surface of the fixture.

Swage-locking pins with both aluminium alloy and stainless steel collars were tested at seven different angles, as shown in Table 8 , in which $\theta_{\mathrm{s}}$ is the angle between the direction of the load and the longitudinal axis of the pin and $F_{\text {s,test }}$ is the test failure load. Each test was repeated three times to evaluate the consistency of performance. The load-carrying 
capacity of all specimens is shown in Table 8 , where $r_{1}, r_{2}$ and $r_{3}$ indicate the serial number of the repeated tests. From the table, it is evident that the tensile strength of the pins with the stainless steel collars is much larger (around $40 \%$ on average) than that of the pins with the aluminium alloy collars. However, since all pins are of the same material and diameter, the resistances of the specimens loaded predominantly in shear $\left(\theta_{\mathrm{s}}=60^{\circ}, 75^{\circ}\right.$ and $\left.90^{\circ}\right)$ are almost the same, regardless of the collar material. Fig. 23 shows the load-axial deformation responses of the swage-locking pins under pure tension, which reveals that the pins with the stainless steel collars have slightly higher stiffnesses than those with the aluminium alloy collars. The deformation of one of the pins with a stainless steel collar was not measured successfully, and hence only two curves are presented for this case.

The failure modes of all the specimens are shown in Fig. 24; three modes of failure were observed: (i) Mode 1: collar pull-out, (ii) Mode 2: shear deformation of the bar combined with collar pull-out and (iii) Mode 3: fracture of the bar. It was found that with increasing values of $\theta_{\mathrm{s}}$, the shear deformation of the pins became increasingly prominent.

Formulae to predict the load-carrying capacity and failure mode of swage-locking pins loaded at different angles are given in Eq. (1) and Eq. (2),

For swage-locking pins loaded predominantly in tension, failing in Mode 1 or Mode 2:

$$
F_{\mathrm{Rd}}=F_{\mathrm{t} 1} / \cos \theta_{\mathrm{s}}
$$

For swage-locking pins loaded predominantly in shear, failing in Mode 3:

$$
\left(\frac{F_{\mathrm{Rd}} \cos \theta_{\mathrm{s}}}{F_{\mathrm{t} 2}}\right)^{2}+\left(\frac{F_{\mathrm{Rd}} \sin \theta_{\mathrm{s}}}{F_{\mathrm{v}}}\right)^{2}=1
$$

in which $F_{\mathrm{Rd}}$ is the design resistance of the swage-locking pin, taken as the lower value (hence defining the critical mode) from Eq.(1) and Eq.(2), $F_{\mathrm{t} 1}$ is the resistance of the collar to pull-out $\left(F_{\mathrm{t} 1}=34.9 \mathrm{kN}\right.$ for the aluminium alloy collar and $F_{\mathrm{t} 1}=49.6 \mathrm{kN}$ for the stainless steel collar are the mean values from the tests performed herein), $F_{\mathrm{v}}$ is the shear resistance 
of the bar, which had a mean value of $53.6 \mathrm{kN}$ from the six experimental results and $F_{\mathrm{t} 2}$ is the tensile resistance of the bar, calculated as $F_{\mathrm{t} 2}=A f_{\mathrm{u}}$, which was equal to $65.4 \mathrm{kN}$ based on the measured material properties of the pin shown in Table 10.

A comparison between the test $F_{\mathrm{s}, \text { test }}$ and predicted $F_{\mathrm{Rd}}$ resistances of the swage-locking pins loaded at different angles is presented in Table 9. A mean value of $F_{\mathrm{Rd}} / F_{\text {s,test }}$ of 1.01 with a coefficient of variation (COV) of 0.058 and maximum relative error of 0.08 for the pins with the aluminium alloy collars and a mean value of $F_{\mathrm{Rd}} / F_{\mathrm{s}, \text { test }}$ of 1.03 with a COV of 0.027 and maximum relative error of 0.06 for the pins with the stainless steel collars were obtained, representing very good agreement. Owing to the limited number of tests, the value of $F_{\mathrm{Rd}} / F_{\mathrm{s} \text {,test }}$ was also compared with the characteristic values from the Student's t distribution [19] which is applicable for small sample sizes. Through application of the distribution model, the confidence intervals associated with a $90 \%$ confidence level in the ratio of $F_{\mathrm{Rd}} / F_{\mathrm{u} \text {,est }}$ for the swage-locking pins with aluminium alloy collars and stainless steel collars were obtained as $(0.96,1.06)$ and $(1.01,1.06)$, respectively.

Owing to the limited number of $12.70 \mathrm{~mm}$ diameter swage-locking pins, only one pure tension test and one pure shear test were conducted, with capacities of $F_{\mathrm{t} 1}=56.7 \mathrm{kN}$ and $F_{\mathrm{v}}=83.5 \mathrm{kN}$, respectively.

\subsection{Material testing}

Tensile coupon tests were conducted according to the standard GB/T 228.1 [20] and AS 1391-2007 [21] to determine the material properties of the aluminium alloy T-stubs and the swage-locking pins. Flat coupons with nominal thicknesses of $8 \mathrm{~mm}, 10 \mathrm{~mm}$ and 12 mm were extracted from the T-stubs. The thickness of the coupons from the web was 8 $\mathrm{mm}$, while the thicknesses of the coupons from the flange were $10 \mathrm{~mm}$ and $12 \mathrm{~mm}$. Note though that T-stubs with $8 \mathrm{~mm}$ flanges, that were machined down from $10 \mathrm{~mm}$, were also tested; the $8 \mathrm{~mm}$ flange material therefore shared the same material properties as the 10 
mm flange material. Each coupon test was repeated three times. The test setup and dimensions of the flat tensile coupons are shown in Fig. 25.

For the swage-locking pins, round tensile coupons were used to carry out the material tests. The ends of the coupons were threaded to facilitate connection within the Zwick/Roell Z050 testing machine. The test setup and nominal dimensions of the tensile coupons are shown in Fig. 26. An extensometer was used to measure the longitudinal strain.

The material properties derived from the tests are summarized in Table 10, in which $E$ is the Young's modulus, $f_{\mathrm{o}}$ is the yield $(0.2 \%$ proof $)$ stress, $f_{\mathrm{u}}$ is the ultimate stress, $\varepsilon_{\mathrm{u}}$ is the strain at the ultimate stress, $n_{\mathrm{p}}$ is the exponent of the Ramberg-Osgood (R-O) expression [22] and $m_{\mathrm{u}}$ is the hardening exponent for the second segment of the two-stage R-O model [23-25]. The stress-strain curves of the aluminium alloy plates are accurately represented by the R-O expression, as shown in Fig. 27 (a)-(c). The two-stage R-O model [23-25] was employed to represent the stress-strain curves of the stainless steel material from the swage-locking pins, as illustrated in Fig. 27 (d), where good agreement can be seen.

\subsection{T-stub test configuration and instrumentation}

All the T-stub tests were conducted in the $300 \mathrm{kN}$ hydraulic testing machine shown in Fig. 28. The T-stubs were aligned with the aid of a laser, before vertical load was applied through the tightly clamped webs.

To overcome measuring difficulties encountered previously [7], an iMETRUM video gauge was adopted to measure the displacement at key positions on the test specimens. The video gauge comprises two main elements: a pair of high-resolution lenses and a host computer. The video gauge could measure displacements at the gauge points (U1-U3 and D1-D3 located as shown in Fig. 28) in three dimensions to an accuracy of $0.001 \mathrm{~mm}$. 
Strain gauges were also applied to the test specimens to monitor strains at the key locations shown in Fig. 29; strain gauge G1 was attached to the web in the direction of loading, while the other strain gauges were attached in a symmetrical configuration to the flange.

The load was applied at a rate of $1.0 \mathrm{~mm} / \mathrm{min}$ under displacement control throughout the whole loading process, and all T-stubs were tested to failure. Load and strain were recorded in real time using an IMP (Isolated Measurement Pod) Data Acquisition System, while the video gauge displacements were recorded simultaneously at the same data recording frequency on its host computer.

\section{Experimental results}

\subsection{Failure modes of $T$-stubs}

According to EN 1999-1-1:2007 (EC9) [26], four distinct modes of failure can be identified for aluminium alloy T-stub joints, as illustrated schematically in Fig. 30: Mode 1 corresponds to flange failure through the development of four hardening plastic hinges, two of which are at the bolt locations with the other two at the web-to-flange junction. Mode 2a corresponds to flange failure with the formation of two hardening plastic hinges at the web-to-flange junction with the bolts at the elastic limit, while Mode $2 \mathrm{~b}$ is defined by the flanges at or above the elastic limit with bolt failure. Mode 3 is characterised by bolt failure only. The failure modes of the tested specimens were determined by examining the deformed shapes and by analysing the data from the strain gauges and video gauge. The strain gauges were utilised to determine the stress levels at the pin locations and at the web-to-flange junction while the video gauge was used to measure the pin elongation and hence to estimate when the elastic limit was reached. From Fig. 31, it can be seen that for Specimen TSDS-8-50, the strain at both the pin location and at the web-to-flange junction exceeded the yield strain, indicating Mode 1 failure, while for Specimen TSDS-10-20, the 
yield strain was only reached at the web-to-flange junction, indicating Mode 2a failure. The failure modes determined using the procedures described above are summarized in Table 11.

The failure modes of the test specimens are compared in Fig. 32 to assess the influence of (a) the distance between the pins and the web, (b) the flange thickness, (c) the collar type and (d) the number of rows of pins. The following observations are made:

(a) Influence of the distance between the pins and the web $(m+0.8 r)$, as defined in Fig. 2: For series TSDA-8-, although the failure modes did not change with increasing distance between the pins and the web, the ultimate deformation increased significantly. For series TSDA-10-, on the other hand, the failure modes changed from Mode 3 to Mode 1 (as shown in Fig. 32 (a)) as the distance $m+0.8 r$ increased from 20 to $50 \mathrm{~mm}$, indicating that the distance between the pins and the web plays an important role in determining the failure mode.

(b) Influence of flange thickness $t_{\mathrm{f}}$ : Comparing the failure modes of Specimens TSDA8-30, TSDA-10-30 and TSDA-12-30, the influence of the flange thickness can be clearly seen. With increasing flange thickness, failure of the swage-locking pins occurs earlier relative to failure of the flanges, and the ultimate behaviour of the specimens tend to become governed by the pins; the deformation capacity of the specimens also reduced with increasing flange thickness.

(c) Influence of collar type: Fig. 32 (c) shows the effects of collar type on the failure modes of the T-stubs. Clearly, the pins with the stainless steel collars exhibited higher load-carrying capacity than those with the aluminium alloy collars. In fact, the pins with the stainless steel collars did not fail in any of the T-stub tests.

(d) Influence of the number of rows of pins: The deformation at peak load of the T-stubs with two rows of pins was greater than that for T-stubs with a single row of pins. For 
the Specimens TSDA-10-30 and TDDA-10-30-30 - see Fig. 32 (d), adding a row of pins changed the failure mode from pin failure to flange cracking, though for Specimens TSSA-12-30 and TDSA-12-30-38, pin failure occurred in the case of both a single and double row of pins.

From Fig. 32, it can be seen that flange fracture does not occur at the web-to-flange junction, where the maximum bending moment arises, but in the flat portion of the flange

- this is due to the presence of the fillets and is the reason for the use of $m$ instead of $m+0.8 r$ for defining the distance between the bolt location and the plastic hinges near the web-to-flange junction in the EC9 [26] design formulae. It can also be observed that cracking of the flanges always initiated on the side of the pin collar; this is due to the different size of the head and collar of the pins, as explained in Section 4.3.

\subsection{Mechanical behaviour of tested T-stubs}

The ultimate resistances $\left(F_{\mathrm{u}, \text { test }}\right)$ and corresponding deformation capacity $(\Delta e)$ of all the tested aluminium alloy extruded T-stubs connected by swage-locking pins are summarised in Table 11, while the load versus axial displacement curves are illustrated in Fig. 33. Note that the curves that showed no peak, or exhibited an abrupt drop in load, are associated with specimens that failed by fracture of the T-stub flange; in these cases, the load at the end point of the curve was taken as the load-carrying capacity. The deformation at peak load of Specimen TSDS-12-20 was not recorded due to the limitations of the video gauge.

It can be observed from Table 11 and Fig. 33 (a) that as the distance between the pins and the web $(m+0.8 r)$ increases, the ultimate resistance and initial stiffness of the T-stubs within each control group decreases, while the deformation capacity increases significantly. As shown in the table and Fig. 33 (b), the influence of the flange thickness $t_{\mathrm{f}}$ on the ultimate resistance and initial stiffness is clear, particularly for specimens failing 
in Mode 1 and Mode 2a, for which increasing flange thickness represents the most effective means of improving $F_{\text {u,test }}$ (e.g. comparing Specimens TSDA-8-40 and TSDA$10-40$, the ultimate resistance of the latter is enhanced by almost $60 \%$ over the former, and comparing Specimens TSDS-8-50 and TSDS-10-50, the ultimate resistance of the latter is enhanced by almost $35 \%$ over the former). In addition, it can be observed that the specimens with pins with the stainless steel collars have larger ultimate resistances but inferior deformation capacity compared to those with aluminium alloy collars; however, if both of the T-stubs fail in Mode 1, without taking full advantage of the pin strength, the collar type has no apparent influence on the structural behaviour, as the curves of Specimens TSDA-10-20 and TSDS-10-20 show in Fig. 33 (c). As for the number of rows of pins, the results shown in Table 11 and Fig. 33 (d) reveal that there is no clear influence on the behaviour of the T-stubs because the second row of pins (further from the T-stub web) barely participate in resisting the applied force and experience little deformation; EC3 [3] therefore recommends that only one row of pins is used to connect the angle cleat to the column flange in beam-to-column joints, as shown in Fig. 19 (b). For the two specimens (TSSA-12-30 and TSSA-12-50) with $12.70 \mathrm{~mm}$ diameter swage-locking pins, although the number of pins was halved compared to Specimens TSDA-12-30 and TSDA12-50, which were connected by $9.66 \mathrm{~mm}$ diameter fasteners, their ultimate resistances were almost the same, confirming the improved load-carrying capacity of the largerdiameter swage-locking pins. 


\section{Evaluation of current design methods and other approaches}

\subsection{EN 1999-1-1:2007 (EC9) [26]}

Design methods for the evaluation of the resistance of aluminium alloy T-stubs are provided in EC9 [26]. According to the four failure modes shown in Fig. 30, the resistances are defined as follows (Eq. (3)- Eq. (6)):

Mode 1:

$$
F_{\mathrm{u}, \mathrm{Rd}}=\frac{2\left(M_{\mathrm{u}, 1}\right)_{\mathrm{w}}+2\left(M_{\mathrm{u}, 1}\right)_{\mathrm{b}}}{m}
$$

Mode 2a:

$$
F_{\mathrm{u}, \mathrm{Rd}}=\frac{2 M_{\mathrm{u}, 2}+n \sum B_{\mathrm{o}}}{m+n}
$$

Mode 2b:

$$
F_{\mathrm{u}, \mathrm{Rd}}=\frac{2 M_{\mathrm{o}, 2}+n \sum B_{\mathrm{u}}}{m+n}
$$

Mode 3:

$$
F_{\mathrm{u}, \mathrm{Rd}}=\sum B_{\mathrm{u}}
$$

in which $F_{\mathrm{u}, \mathrm{Rd}}$ is the design resistance of the T-stub with the partial safety factor $\gamma_{\mathrm{M}}$ set equal to unity, $n=e$ but $\leq 1.25 m$ (see Fig. 20), $B_{\mathrm{o}}$ and $B_{\mathrm{u}}$ are the elastic and ultimate tensile resistances of the swage-locking pins respectively, the values of which are shown in Table $12,\left(M_{\mathrm{u}, 1}\right)_{\mathrm{w}}$ and $M_{\mathrm{u}, 2}$ are the ultimate bending moment resistances of the flange at the flange-to-web junction for Mode 1 and Mode 2a respectively, as given by Eq. (7) and (8), considering different flange effective lengths $\left(l_{\mathrm{eff}, 1}\right.$ and $\left.l_{\mathrm{eff}, 2}\right),\left(M_{\mathrm{u}, 1}\right)_{\mathrm{b}}$ is the ultimate bending moment resistance of the flange at the pin location considering the net area, which can also be calculated from Eq. (7) and $M_{\mathrm{o}, 2}$ is elastic bending moment resistance of the flange, as given in Eq. (9),

$$
\begin{aligned}
& M_{\mathrm{u}, 1}=0.25 t_{\mathrm{f}}^{2} \sum\left(l_{\mathrm{eff}, 1} f_{\mathrm{u}}\right) \frac{1}{k} \\
& M_{\mathrm{u}, 2}=0.25 t_{\mathrm{f}}^{2} \sum\left(l_{\mathrm{eff}, 2} f_{\mathrm{u}}\right) \frac{1}{k}
\end{aligned}
$$




$$
M_{\mathrm{o}, 2}=0.25 t_{\mathrm{f}}^{2} \sum\left(l_{\mathrm{eff}, 2} f_{\mathrm{o}}\right) \frac{1}{k}
$$

where $l_{\mathrm{eff}, 1}$ and $l_{\mathrm{eff}, 2}$ are effective lengths of flange for Mode 1 and Mode 2 respectively, considering different failure modes of T-stubs and the development of different (circular and non-circular) yield line patterns, the formulae for which are presented in EC9 and 1/k is a reduction factor which is given by Eq. (10),

$$
\frac{1}{k}=\frac{f_{\mathrm{o}}}{f_{u}}\left[1+\left(\frac{\varepsilon_{\mathrm{u}}-1.5 \varepsilon_{\mathrm{o}}}{1.5 \varepsilon_{\mathrm{u}}-1.5 \varepsilon_{\mathrm{o}}}\right)\left(\frac{f_{u}-f_{\mathrm{o}}}{f_{\mathrm{o}}}\right)\right]
$$

where $\varepsilon_{\mathrm{u}}$ is the ultimate strain of the T-stub flange material and $\varepsilon_{\mathrm{o}}=f_{\mathrm{o}} / E$ is the yield strain.

A comparison between the test resistances and the predicted resistances calculated according to EC9 $F_{\mathrm{EC} 9}$ is presented in Table 11; the EC9 resistance was taken as the smallest value for the above four possible failure modes, although the predicted failure mode sometimes differed from that observed in the corresponding experiment. For the Tstubs with more than one row of pins, EC9 does not provide explicit guidance, so the design resistance for Specimens TDDA-10-30-25 and TDDA-10-30-30 was taken as that for Specimen TSDA-10-30; similarly, the design resistance of Specimens TDSA-12-3032 and TDSA-12-30-38 was taken as that for Specimen TSSA-12-30.

From Table 11, it is evident that EC9 yields safe-sided, but unduly conservative predictions of the ultimate resistance of aluminium alloy extruded T-stubs connected by swage-locking pins, with the mean value of $F_{\mathrm{EC}} / F_{\mathrm{u} \text {,test }}$ for all the specimens being 0.735 and the coefficient of variation (COV) being 0.090 . The coefficient of determination $\left(R^{2}\right)$ was also calculated to evaluate the goodness-of-fit of the predictions relative to the experimental results; an $R^{2}$ value of 0.953 was obtained considering the full experimental data set. Improved design provisions are explored in the following sections. 


\subsection{Continuous strength method (CSM)}

The continuous strength method (CSM) is a recently developed deformation-based design framework that allows for the beneficial influence of strain hardening; the method has been developed for the design of aluminium alloy cross-sections over the full range of section slenderness [27-29]. The two key features of the CSM are: (i) a base curve that defines the level of strain $\left(\varepsilon_{\mathrm{csm}}\right)$ that a cross-section can tolerate as a function of section slenderness and (ii) a material model that can capture strain hardening.

For the Mode 1 and Mode 2a failure mechanisms, hardening plastic hinges form in the T-stub flange, as illustrated in Fig. 34, which also shows the corresponding analytical model behind the EC9 design method for T-stubs in tension. In the model, the T-stub flange is represented as a continuous beam, the swage-locking pins are modelled using springs and, taking advantage of symmetry, a roller support is located at the flange-to-web junction. For the hardening plastic hinges, $\left(M_{\mathrm{u}, 1}\right)_{\mathrm{w}},\left(M_{\mathrm{u}, 1}\right)_{\mathrm{b}}$ and $M_{\mathrm{u}, 2}$ can be calculated using the CSM. The maximum strain that the cross-section at the web-to-flange junction and at the pin location can tolerate is the ultimate strain of material i.e. $\varepsilon_{\mathrm{u}}$. Thus, assuming a linearly varying strain distribution through the flange thickness and adopting the CSM material model, the corresponding moment resistance can be obtained. The CSM elastic, linear hardening material model established for aluminium alloys in [27] is used, featuring the Young's modulus $E$ and the CSM strain hardening modulus $E_{\mathrm{sh}}$, which is defined in Eq. (11),

$$
E_{\mathrm{sh}}=\frac{f_{\mathrm{u}}-f_{\mathrm{o}}}{0.5 \varepsilon_{\mathrm{u}}-\varepsilon_{\mathrm{o}}}
$$

The predicted ultimate resistances $F_{\mathrm{csm}}$ of the T-stubs, derived by using the CSM to calculate the moment resistance at the plastic hinges, are listed in Table 11, and can be seen to be more accurate and less scattered compared to the resistance predictions from 
EC9. Yuan et al. [5] also reported better predicted results for stainless steel T-stubs using the CSM, rather than the design rules in Eurocode 3. Further improvements are sought in the following sub-section.

\subsection{Proposed design method based on the CSM}

Although in the above comparisons the strain hardening behaviour of the plastic hinges was captured using the CSM, the predicted ultimate resistances of extruded aluminium alloy T-stubs connected by swage-locking pins remained substantially below the test results, highlighting the need for a new design method considering the particular mechanical response of the studied T-stub system, as well as the strain hardening behaviour of the material.

For the Mode 1 failure mechanism, failure is caused by the formation of hardening plastic hinges in the T-stub flange. However, because of the existence of the pin head and collar, the plastic hinges cannot develop at the pin location, as noted and accounted for in the case of steel T-stubs in EN 1993-1-8 (EC3) [3], but the design method presented therein is not suitable for aluminium alloy T-stubs. Hence, a modified expression for predicting the ultimate resistance of aluminium alloy T-stubs failing in Mode 1 is proposed, as given by:

$$
F_{\text {prop }}=\frac{4\left(M_{\mathrm{u}, 1}\right)_{\mathrm{w}}}{m^{\prime}}
$$

in which the definition of $m^{\prime}$ is illustrated in Fig. 35 and given by Eq. (13), where $w_{\mathrm{h}}$ is the diameter of the head of the pin and $w_{\mathrm{c}}$ is the diameter of the collar. Note that the thin collar flange, shaded in grey in Fig. 35, is not included in the definition of $w_{\mathrm{c}}$ since it is not stiff enough to provide restraint to the T-stub. With the revised definition of $m^{\prime}$, the hinge location shifts from the centre of the pin, with a moment resistance $\left(M_{\mathrm{u}, 1}\right)_{\mathrm{b}}$ allowing for 
the presence of the pin holes, to the edge of the head of the pin, where the moment resistance is $\left(M_{\mathrm{u}, 1}\right)_{\mathrm{w}}$.

$$
m^{\prime}=d-0.8 r-\min \left(\frac{w_{\mathrm{h}}}{2}, \frac{w_{\mathrm{c}}}{2}\right)
$$

The diameter of the pin head often differs from that of the collar; in such instances, the resistance of the T-stub should be controlled by the side with the smaller diameter. For all the swage-locking pins considered herein, $w_{\mathrm{h}}$ is larger than $w_{\mathrm{c}}$ suggesting that failure of the T-stubs flange should occur first on the collar side of the pin; this indeed proved to be the case in all tests, as confirmed by the experimental failure modes shown in Fig. 32.

Mode $2 \mathrm{a}$ is a distinct failure mode associated with aluminium alloy T-stubs due to the inferior ductility of aluminium alloys relative to steel. In Mode 2a, although failure of the specimens is, as in Mode 1, caused by the formation of plastic hinges in the T-stub flange, the restraint provided by the head of the pin and the collar at the pin location is not as stiff as in the Mode 1, due to the tensile and bending deformations of the swage-locking pins. The analytical model for Mode $2 \mathrm{a}$ is illustrated in Fig. 36, neglecting the difference between the head of the pin and the collar. To satisfy the requirement for compatibility of deformations, bending of the flange also results in bending of the pins. The design method in EC9 [26] neglects the additional moment resistance $\left(M_{\mathrm{a}}\right)$ resulting from the restraining effect of the head of the pin and the collar, which is beneficial to the load-carrying capacities of the T-stubs, leading to overly-conservative resistance predictions. If this effect is included, moment equilibrium at the web-to-flange junction in the ultimate state gives:

$$
Q(m+n)+\frac{\sum M_{\mathrm{a}}}{2}-\frac{\sum B_{\mathrm{o}}}{2} m+M_{\mathrm{u}, 2}=0
$$

The relationship between the prying force $Q$ and the applied load $F_{\text {prop }}$ is given by Eq. (15), 


$$
2 Q+F_{\text {prop }}=\sum B_{\text {o }}
$$

Hence, the proposed resistance $F_{\text {prop }}$ for failure in Mode 2a is given by as Eq. (16),

$$
F_{\text {prop }}=\frac{2 M_{\mathrm{u}, 2}+n \sum B_{\mathrm{o}}+\sum M_{\mathrm{a}}}{m+n}
$$

The next step is to calculate $M_{\mathrm{a}}$ by applying Euler-Bernoulli beam theory for half of a swage-locking pin modelled as a cantilever beam under pure bending moment - see Eq. (17). Since the pin is under uniform bending i.e. there is no transverse shear force, EulerBernoulli beam theory remains applicable despite the low length-to-height ratio of the element. In the equation, $x$ is the distance from the plane of symmetry in loading direction, $\theta$ is the rotation angle of the cross-section of the pin, $E_{\mathrm{p}}$ is the Young's modulus of the material of the pin and $d_{\text {pin }}$ is the pin diameter. Applying the boundary condition of $\theta=0$ at Point $O$ (i.e. at $x=0$ ), the constant $\mathrm{C}$ is found to be zero. At Point $P, x=t_{\mathrm{f}}$ (neglecting the small elongation of the pin), and the rotation angle $\theta$ of the end section is equal to $\alpha \approx$ $\tan \alpha=\Delta_{0} / 2 n$, in which $\Delta_{0}$ (the value is shown in Table 12) is the pin elongation at the elastic limit.

$$
\theta(x) \approx \tan \theta(x)=\frac{M_{\mathrm{a}} x+\mathrm{C}}{E_{p}\left(\frac{\pi d_{\mathrm{pin}}^{4}}{64}\right)}
$$

By substituting $\alpha$ into Eq. (17), we obtain the definition of $M_{\mathrm{a}}$ given by Eq. (18). Note that, the additional moment resistance $M_{\mathrm{a}}$ does not arise in Mode 1 and has little or no influence on Mode $2 \mathrm{~b}$ and Mode 3; hence, the additional moment resistance $M_{\mathrm{a}}$ is only considered for Mode 2a.

$$
M_{\mathrm{a}}=\frac{\Delta_{0}}{2 n} \frac{E_{p}}{t_{\mathrm{f}}}\left(\frac{\pi d_{\mathrm{pin}}^{4}}{64}\right)
$$


The resistance predictions obtained through application of proposed design method are presented in Table 11. From the table, it can be seen that the proposed method provides good predictions of the experimental results, with a mean value of $F_{\text {prop }} / F_{\text {u,test }}$ of 0.918 , improving the design accuracy by almost $25 \%$ over EC 9 .

\section{Conclusions}

Thirty tests were conducted in this paper to investigate the structural behaviour of extruded aluminium alloy T-stubs connected by swage-locking pins under monotonic loading. The specimens were designed with different geometric parameters, including the distance between the pins and the web $(m+0.8 r)$, the thickness of the flange $t_{\text {f }}$, the pin diameter $d_{\text {pin }}$, the collar type (aluminium or stainless steel) and the number of rows of pins, to study their influence on the load-carrying behaviour of the T-stubs. The main conclusions are drawn as follows:

1. Prior to the tests on the T-stubs, material tests on aluminium alloy coupons cut from the T-stubs and stainless steel coupons machined from the pins were performed. Fortytwo component tests on the swage-locking pins under pure tension, pure shear and a combination of tension and shear were also conducted. Three different failure modes were observed and a design method to predict the load-carrying capacities of the pins was proposed.

2. In the experimental programme on the extruded aluminium alloy T-stubs, the four failure modes identified in EC9 were observed. The test failure mechanisms, ultimate resistances, load versus vertical displacement responses and deformation capacities were determined, reported and utilized to analyse the influence of a number of key parameters. The results showed that with decreasing distance between the pins and the web or increasing thickness of the T-stub flange, the ultimate resistance and the initial 
stiffness of the T-stubs increased significantly, though decreasing the distance between the pins and the web led to reduced deformation capacity. Through their influence on the load-carrying capacity of the swage-locking pins, the collar type and pin diameter also affected the structural behaviour of the T-stubs. Increasing the number of rows of pins resulted in no significant change to the resistance of the T-stubs.

3. The experimental results were used to evaluate the accuracy of the design methods in EC9 - the comparisons presented showed that the code generally underestimates the load-carrying capacity of extruded aluminium alloy T-stubs connected by swagelocking pins. Through application of the CSM, the accuracy of the predictions was improved. Finally, a new design method, based on the CSM, was proposed and shown to provide substantially improved agreement with the experimental results.

4. Future work will feature finite element modelling and parametric analyses to develop a more comprehensive understanding of the behaviour of aluminium alloy T-stubs connected by swage-locking pins; the reliability of the design rules proposed herein will then be evaluated against the resulting dataset.

\section{Acknowledgements}

The authors would like to acknowledge the financial support of the National Natural Science Foundation of China (Grant No. 51878377). The authors would also like to thank Tongle Jin, Ying Yu and Wei Zhang for their contribution to the testing program as well as the support of the Key Laboratory of Civil Engineering Safety and Durability of China Education Ministry at Tsinghua University. 


\section{REFERENCES}

[1] Wang YQ, Wang ZX, Yin FX, Yang L, Shi YJ, Yin J. Experimental study and finite element analysis on the local buckling behavior of aluminium alloy beams under concentrated loads. Thin-Walled Structures. 2016;105:44-56.

[2] De Matteis G, Brando G. Analysis of aluminium beam-to-column joints by the component method: existing studies and research needs. Key Engineering Materials. 2016;710:409-14.

[3] Jaspart JP. General report: session on connections. Journal of Constructional Steel Research. 2000;55(1-3):69-89.

[4] EN 1993-1-8 Eurocode 3: Design of steel structures - Part 1.8: Design of joints. European Committee for Standardization (CEN), Brussels; 2005.

[5] Yuan HX, Hu S, Du XX, Yang L, Cheng XY, Theofanous M. Experimental behaviour of stainless steel bolted T-stub connections under monotonic loading. Journal of Constructional Steel Research. 2019;152:213-24.

[6] Faella C, Piluso V, Rizzano G. Experimental analysis of bolted connections: snug versus preloaded bolts. Journal of Structural Engineering. 1998;124(7):765-74.

[7] Coelho AM, Bijlaard FS, Gresnigt N, da Silva LS. Experimental assessment of the behaviour of bolted T-stub connections made up of welded plates. Journal of Constructional Steel Research. 2004;60(2):269-311.

[8] Girão Coelho AM, Simões da Silva L, Bijlaard FS. Finite-element modeling of the nonlinear behavior of bolted T-stub connections. Journal of Structural Engineering. 2006;132(6):918-28.

[9] Abidelah A, Bouchaïr A, Kerdal DE. Influence of the flexural rigidity of the bolt on the behavior of the T-stub steel connection. Engineering Structures. 2014;81:181-94. 
[10] Zhao MS, Lee CK, Chiew SP. Tensile behavior of high performance structural steel T-stub joints. Journal of Constructional Steel Research. 2016;122:316-25.

[11] Wang ZY, Tizani W, Wang QY. Strength and initial stiffness of a blind-bolt connection based on the T-stub model. Engineering Structures. 2010;32(9):2505-17.

[12] De Matteis G, Della Corte G, Mazzolani FM. Experimental analysis of aluminium T-stubs: tests under monotonic loading. InXVIII Congresso CTA 2001 (Vol. 2, pp. 29-40). ACS ACAI Servizi srl.

[13] De Matteis G, Della Corte G, Mazzolani FM. Experimental analysis of aluminium T-stubs: tests under cyclic loading. In: The International Conference on Advances in Structures, Sydney; 2003.

[14] De Matteis G, Brescia M, Formisano A, Mazzolani FM. Behaviour of welded aluminium T-stub joints under monotonic loading. Computers \& Structures. 2009;87(15-16):990-1002.

[15] De Matteis G, Naqash MT, Brando G. Effective length of aluminium T-stub connections by parametric analysis. Engineering Structures. 2012;41:548-61.

[16] Xu H, Guo XN, Luo YF. The load-bearing capacity of aluminum alloy T-stub joints. Advanced Materials Research. 2011;261:765-9.

[17] GB 50429-2007, Code for design of aluminium structures. MOHURD, Beijing; 2007. (in Chinese)

[18] Wang ZX, Wang YQ and Ouyang YW. Multi-angle adjustable device for testing sample simultaneously bearing tensile and shear forces. CN108169016A; 2018. (Patent in China)

[19] Student. The probable error of a mean. Biometrika. 1908;1:1-25.

[20] GB/T 228.1 Metallic materials - tensile testing - Part 1: Method of test at room temperature. Standards Press of China, Beijing; 2011 (in Chinese). 
[21] AS 1391-2007, Metallic Materials - Tensile Testing at Ambient Temperature. Standards Australia, Sydney; 2007.

[22] Ramberg W, Osgood W R. "Description of Stress-Strain Curves by Three Parameters", Technical Note No. 902, National Advisory Committee for Aeronautics, Washington, D.C., USA; 1943.

[23] Gardner L, Yun X. Description of stress-strain curves for cold-formed steels. Construction and Building Materials. 2018;189:527-38.

[24] Mirambell E, Real E. On the calculation of deflections in structural stainless steel beams: an experimental and numerical investigation. Journal of Constructional Steel Research. 2000;54(1):109-33.

[25] Arrayago I, Real E, Gardner L. Description of stress-strain curves for stainless steel alloys. Materials and Design. 2015;87:540-52.

[26] EN 1999-1-1:2007 Eurocode 9: Design of aluminium structures - Part 1-1: General structural rules. European Committee for Standardization (CEN), Brussels; 2007.

[27] Su MN, Young B, Gardner L. The continuous strength method for the design of aluminium alloy structural elements. Engineering Structures. 2016;122:338-48.

[28] Su MN, Young B, Gardner L. Testing and design of aluminum alloy cross sections in compression. Journal of Structural Engineering. 2014;140(9):04014047.

[29] Su MN, Young B, Gardner L. Deformation-based design of aluminium alloy beams. Engineering Structures. 2014;80:339-49. 
Table 1. Dimensions of tested T-stubs

\begin{tabular}{|c|c|c|c|c|c|c|c|c|c|c|}
\hline Type & Label & $\begin{array}{c}t_{\mathrm{f}} \\
(\mathrm{mm})\end{array}$ & $\begin{array}{c}m+0.8 r \\
(\mathrm{~mm})\end{array}$ & $\begin{array}{c}d_{\text {pin }} \\
(\mathrm{mm})\end{array}$ & $\begin{array}{c}b_{\mathrm{f}} \\
(\mathrm{mm})\end{array}$ & $\begin{array}{c}e \\
(\mathrm{~mm})\end{array}$ & $\begin{array}{c}e_{1} \\
(\mathrm{~mm})\end{array}$ & $\begin{array}{c}e_{2} \\
(\mathrm{~mm})\end{array}$ & $\begin{array}{c}b \\
(\mathrm{~mm})\end{array}$ & $\begin{array}{r}F_{\mathrm{p}, \mathrm{C}} \\
(\mathrm{kN}) \\
\end{array}$ \\
\hline TSD & TSDA-8-20 & 8.03 & 20.41 & 9.66 & 148.05 & 49.62 & - & - & 79.72 & 23.71 \\
\hline TSD & TSDA-8-30 & 8.07 & 30.36 & 9.66 & 148.06 & 39.67 & - & - & 79.48 & 23.71 \\
\hline TSD & TSDA-8-40 & 8.04 & 40.51 & 9.66 & 148.00 & 29.49 & - & - & 78.98 & 23.71 \\
\hline TSD & TSDA-8-50 & 8.03 & 50.31 & 9.66 & 148.04 & 19.71 & - & - & 79.39 & 23.71 \\
\hline TSD & TSDA-10-20 & 10.10 & 19.93 & 9.66 & 147.59 & 49.87 & - & - & 80.39 & 23.71 \\
\hline TSD & TSDA-10-30 & 10.11 & 31.89 & 9.66 & 148.04 & 38.13 & - & - & 80.60 & 23.71 \\
\hline TSD & TSDA-10-40 & 10.13 & 40.79 & 9.66 & 148.04 & 29.23 & - & - & 80.78 & 23.71 \\
\hline TSD & TSDA-10-50 & 10.10 & 51.95 & 9.66 & 147.87 & 17.99 & - & - & 80.89 & 23.71 \\
\hline TSD & TSDA-12-20 & 12.02 & 20.65 & 9.66 & 147.48 & 49.09 & - & - & 80.57 & 23.71 \\
\hline TSD & TSDA-12-30 & 12.05 & 30.47 & 9.66 & 147.36 & 39.21 & - & - & 80.32 & 23.71 \\
\hline TSD & TSDA-12-40 & 12.05 & 41.79 & 9.66 & 147.35 & 27.89 & - & - & 80.56 & 23.71 \\
\hline TSD & TSDA-12-50 & 12.19 & 51.00 & 9.66 & 148.41 & 19.21 & - & - & 80.48 & 23.71 \\
\hline TDD & TDDA-10-30-25 & 10.01 & 29.84 & 9.66 & 167.95 & - & 25.33 & 24.81 & 80.09 & 23.71 \\
\hline TDD & TDDA-10-30-30 & 10.05 & 29.90 & 9.66 & 168.12 & - & 20.36 & 29.80 & 78.74 & 23.71 \\
\hline TSS & TSSA-12-30 & 12.21 & 28.07 & 12.70 & 148.20 & 42.03 & - & - & 81.37 & 24.63 \\
\hline TSS & TSSA-12-50 & 12.17 & 48.16 & 12.70 & 148.20 & 21.94 & - & - & 79.02 & 24.63 \\
\hline TDS & TDSA-12-30-32 & 12.26 & 27.47 & 12.70 & 179.88 & - & 26.73 & 31.74 & 80.34 & 24.63 \\
\hline TDS & TDSA-12-30-38 & 12.00 & 27.84 & 12.70 & 179.25 & - & 20.10 & 37.69 & 77.13 & 24.63 \\
\hline TSD & TSDS-8-20 & 8.06 & 20.28 & 9.66 & 148.14 & 49.79 & - & - & 79.76 & 29.42 \\
\hline TSD & TSDS-8-30 & 8.01 & 30.49 & 9.66 & 148.12 & 39.57 & - & - & 79.60 & 29.42 \\
\hline TSD & TSDS-8-40 & 8.01 & 40.41 & 9.66 & 148.06 & 29.62 & - & - & 78.27 & 29.42 \\
\hline TSD & TSDS-8-50 & 8.00 & 50.58 & 9.66 & 148.09 & 19.47 & - & - & 80.62 & 29.42 \\
\hline TSD & TSDS-10-20 & 10.06 & 20.59 & 9.66 & 148.19 & 49.51 & - & - & 79.75 & 29.42 \\
\hline TSD & TSDS-10-30 & 10.10 & 30.41 & 9.66 & 148.11 & 39.65 & - & - & 81.26 & 29.42 \\
\hline TSD & TSDS-10-40 & 10.02 & 40.49 & 9.66 & 148.10 & 29.56 & - & - & 80.26 & 29.42 \\
\hline TSD & TSDS-10-50 & 10.14 & 50.62 & 9.66 & 148.09 & 19.43 & - & - & 79.98 & 29.42 \\
\hline TSD & TSDS-12-20 & 12.15 & 20.46 & 9.66 & 147.78 & 49.43 & - & - & 78.75 & 29.42 \\
\hline TSD & TSDS-12-30 & 12.06 & 30.63 & 9.66 & 148.02 & 39.38 & - & - & 80.51 & 29.42 \\
\hline TSD & TSDS-12-40 & 12.06 & 40.53 & 9.66 & 148.04 & 29.49 & - & - & 79.52 & 29.42 \\
\hline TSD & TSDS-12-50 & 11.99 & 50.67 & 9.66 & 147.90 & 19.28 & - & - & 79.88 & 29.42 \\
\hline
\end{tabular}

Table 2. Summary of loading angle and test results on swage-locking pins

\begin{tabular}{ccccccccc}
\hline & \multicolumn{3}{c}{$F_{\mathrm{s}, \text { test }}$ of pins with aluminium alloy } & \multicolumn{4}{c}{$F_{\mathrm{s}, \text { test }}$ of pins with stainless steel } \\
collars $(\mathrm{kN})$
\end{tabular}


Table 3. Comparison of experimental resistances $F_{\text {s,test }}$ with design values $F_{\mathrm{Rd}}$

\begin{tabular}{ccccc}
\hline Angle & \multicolumn{2}{l}{ Pins with aluminium alloy collars } & \multicolumn{2}{c}{ Pins with stainless steel collars } \\
\cline { 2 - 5 }$\theta_{\mathrm{s}}\left({ }^{\circ}\right)$ & $F_{\mathrm{Rd}}(\mathrm{kN})$ & $F_{\mathrm{Rd}} / F_{\mathrm{s}, \text { test }}$ & $F_{\mathrm{Rd}}(\mathrm{kN})$ & $F_{\mathrm{Rd}} / F_{\mathrm{s}, \text { test }}$ \\
\hline 0 & - & - & - & - \\
15 & 36.12 & 1.01 & 51.32 & 1.01 \\
30 & 40.29 & 0.92 & 57.24 & 1.00 \\
45 & 49.34 & 1.01 & 58.62 & 1.05 \\
60 & 55.95 & 1.07 & 55.95 & 1.06 \\
75 & 54.21 & 1.04 & 54.21 & 1.05 \\
90 & - & - & - & - \\
\hline \multicolumn{2}{c}{ Mean value } & 1.01 & & 1.03 \\
COV & 0.058 & & 0.027 \\
Maximum relative error & 0.08 & & 0.06 \\
\hline
\end{tabular}

Table 4. Summary of measured material properties of T-stubs and swage-locking pins

\begin{tabular}{lrccccc}
\hline $\begin{array}{l}\text { T-stub and swage-locking pin } \\
\text { material }\end{array}$ & $E(\mathrm{MPa})$ & $f_{\mathrm{o}}(\mathrm{MPa})$ & $f_{\mathrm{u}}(\mathrm{MPa})$ & $\varepsilon_{\mathrm{u}}(\%)$ & $n_{\mathrm{p}}$ & $m_{\mathrm{u}}$ \\
\hline Web of T-stub $(8 \mathrm{~mm})$ & 69,400 & 263.7 & 298.4 & 8.44 & 31.8 & - \\
Flange of T-stub $(8 / 10 \mathrm{~mm})$ & 69,600 & 253.4 & 290.2 & 9.27 & 30.0 & - \\
Flange of T-stub $(12 \mathrm{~mm})$ & 67,200 & 250.6 & 274.2 & 5.26 & 35.5 & - \\
9.66 mm swage-locking pin & 204,200 & 581.7 & 891.6 & 17.73 & 7.9 & 18.7 \\
12.70 mm swage-locking pin & 185,100 & 635.2 & 994.9 & 4.30 & 6.9 & 8.5 \\
\hline
\end{tabular}


Table 5. Summary of experimental results of T-stubs and comparison with design methods

\begin{tabular}{|c|c|c|c|c|c|c|c|c|c|}
\hline Label & $\begin{array}{c}\text { Failure } \\
\text { modes }\end{array}$ & $\begin{array}{l}F_{\text {u,test }} \\
(\mathrm{kN})\end{array}$ & $\begin{array}{c}\Delta e \\
(\mathrm{~mm})\end{array}$ & $\begin{array}{l}F_{\mathrm{EC} 9} \\
(\mathrm{kN})\end{array}$ & $\begin{array}{l}F_{\mathrm{EC} 9} / \\
F_{\mathrm{u}, \text { test }}\end{array}$ & $\begin{array}{l}F_{\mathrm{csm}} \\
(\mathrm{kN})\end{array}$ & $\begin{array}{l}F_{\mathrm{csm}} / \\
F_{\mathrm{u}, \text { test }}\end{array}$ & $\begin{array}{l}F_{\text {prop }} \\
(\mathrm{kN})\end{array}$ & $\begin{array}{l}F_{\text {prop }} / \\
F_{\text {u,test }}\end{array}$ \\
\hline TSDA-8-20 & $2 a$ & 94.81 & 2.70 & 71.96 & 0.759 & 74.37 & 0.784 & 90.64 & 0.956 \\
\hline TSDA-8-30 & 1 & 66.15 & 5.50 & 45.89 & 0.694 & 47.43 & 0.717 & 76.17 & 1.151 \\
\hline TSDA-8-40 & 1 & 48.40 & 6.95 & 32.92 & 0.680 & 34.02 & 0.703 & 49.40 & 1.021 \\
\hline TSDA-8-50 & 1 & 37.82 & 10.64 & 26.16 & 0.692 & 27.04 & 0.715 & 37.23 & 0.984 \\
\hline TSDA-10-20 & 3 & 116.67 & 1.15 & 91.90 & 0.788 & 92.92 & 0.796 & 101.25 & 0.868 \\
\hline TSDA-10-30 & $2 b$ & 96.67 & 5.91 & 69.28 & 0.717 & 71.61 & 0.741 & 82.82 & 0.857 \\
\hline TSDA-10-40 & $2 a$ & 77.35 & 10.40 & 53.22 & 0.688 & 55.01 & 0.711 & 69.71 & 0.901 \\
\hline TSDA-10-50 & 1 & 59.75 & 12.62 & 42.56 & 0.712 & 43.99 & 0.736 & 55.83 & 0.934 \\
\hline TSDA-12-20 & 3 & 123.09 & 2.34 & 101.07 & 0.821 & 101.92 & 0.828 & 108.37 & 0.880 \\
\hline TSDA- & 3 & 106.23 & 3.13 & 86.95 & 0.818 & 87.49 & 0.824 & 90.13 & 0.848 \\
\hline TSDA- & $2 b$ & 90.74 & 4.30 & 69.96 & 0.771 & 70.46 & 0.777 & 73.43 & 0.809 \\
\hline TSDA & $2 b$ & 68.93 & 6.62 & 55.54 & 0.806 & 56.05 & 0.813 & 60.28 & 0.875 \\
\hline TDDA-10 & $2 \mathrm{a}$ & 101.32 & 6.62 & 69.28 & 0.684 & 71.61 & 0.707 & 82.82 & 0.817 \\
\hline TDDA-1 & $2 \mathrm{a}$ & 100.49 & 6.03 & 69.28 & 0.689 & 71.61 & 0.713 & 82.82 & 0.824 \\
\hline TSSA-12-30 & $2 b$ & 93.64 & 1.63 & 74.19 & 0.792 & 74.81 & 0.799 & 80.38 & 0.858 \\
\hline TSS & $2 b$ & 59.58 & 3.36 & 49.19 & 0.826 & 49.71 & 0.834 & 57.08 & 0.958 \\
\hline TDSA- & $2 b$ & 106.88 & 2.69 & 74.19 & 0.694 & 74.81 & 0.700 & 80.38 & 0.752 \\
\hline TDSA- & $2 b$ & 99.24 & 2.46 & 74.19 & 0.748 & 74.81 & 0.754 & 80.38 & 0.810 \\
\hline TSD & 1 & 106.95 & 2.83 & 73.08 & 0.683 & 75.54 & 0.706 & 108.18 & 1.012 \\
\hline TSDs & 1 & 73.88 & 5.60 & 45.07 & 0.610 & 46.58 & 0.631 & 74.28 & 1.005 \\
\hline TSDS- & 1 & 51.66 & 6.40 & 32.42 & 0.628 & 33.51 & 0.649 & 48.59 & 0.941 \\
\hline TSDS-8-50 & 1 & 42.79 & 13.40 & 26.28 & 0.614 & 27.16 & 0.635 & 37.17 & 0.869 \\
\hline TSDS-10-20 & $2 \mathrm{a}$ & 147.98 & 3.61 & 107.70 & 0.728 & 108.66 & 0.734 & 116.21 & 0.785 \\
\hline TSDS-10-30 & 1 & 100.21 & 4.91 & 73.60 & 0.734 & 76.07 & 0.759 & 101.57 & 1.014 \\
\hline TSDS-10-40 & 1 & 76.07 & 9.32 & 52.11 & 0.685 & 53.86 & 0.708 & 77.76 & 1.022 \\
\hline TSDS-10-50 & 1 & 58.04 & 8.21 & 41.80 & 0.720 & 43.20 & 0.744 & 59.18 & 1.020 \\
\hline TSDS-12-20 & $2 a$ & 150.13 & - & 118.86 & 0.792 & 119.72 & 0.797 & 126.07 & 0.840 \\
\hline TSDS-12-30 & 1 & 115.98 & 2.61 & 98.63 & 0.850 & 100.78 & 0.869 & 107.37 & 0.926 \\
\hline TSDS-12-40 & 1 & 86.49 & 3.28 & 71.45 & 0.826 & 73.00 & 0.844 & 89.04 & 1.029 \\
\hline TSDS-12-50 & 1 & 70.18 & 4.83 & 55.83 & 0.796 & 57.04 & 0.813 & 68.66 & 0.978 \\
\hline \multicolumn{2}{|c|}{ Mean Value } & & & & 0.735 & & 0.751 & & 0.918 \\
\hline \multicolumn{2}{|l|}{$\mathrm{COV}$} & & & & 0.090 & & 0.083 & & 0.101 \\
\hline \multirow{2}{*}{\multicolumn{2}{|c|}{ Maximum relative error }} & & & & 0.390 & & 0.369 & & 0.248 \\
\hline & & & & 0.953 & & 0.957 & & 0.901 & \\
\hline
\end{tabular}

Table 6. Geometric properties and resistances of swage-locking pins with different diameters and collar types

\begin{tabular}{lccccc}
\hline \multicolumn{1}{c}{$\begin{array}{c}\text { Swage-locking pin diameter } \\
(\mathrm{mm}) \text { and collar type }\end{array}$} & $\Delta_{\mathrm{o}}(\mathrm{mm})$ & $w_{\mathrm{c}}(\mathrm{mm})$ & $w_{\mathrm{h}}(\mathrm{mm})$ & $B_{\mathrm{o}}(\mathrm{kN})$ & $B_{\mathrm{u}}(\mathrm{kN})$ \\
\hline 9.66-aluminium alloy collar & 0.38 & 15.35 & 19.05 & 27.76 & 34.89 \\
9.66-stainless steel collar & 0.37 & 15.11 & 19.05 & 34.48 & 49.57 \\
12.70-aluminium alloy collar & 0.50 & 20.32 & 22.99 & 40.84 & 56.65 \\
\hline
\end{tabular}




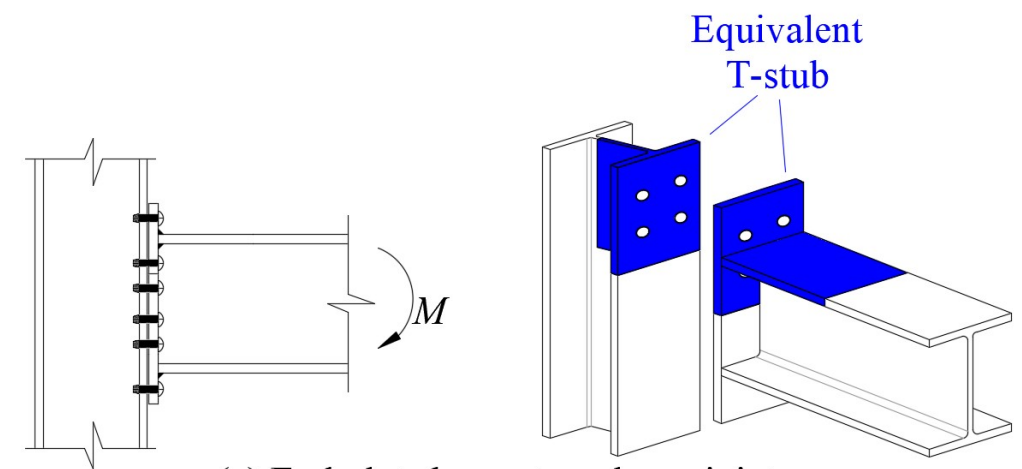

(a) End plate beam-to-column joint
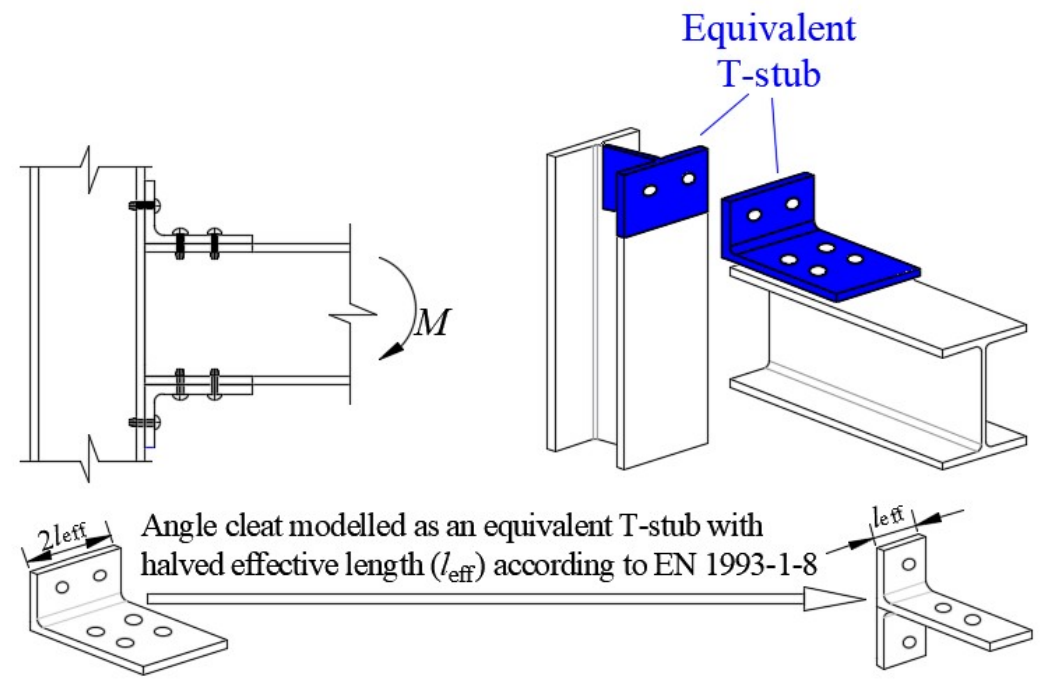

(b) Angle cleat beam-to-column joint

Fig. 1. Equivalent T-stubs in beam-to-column joints 


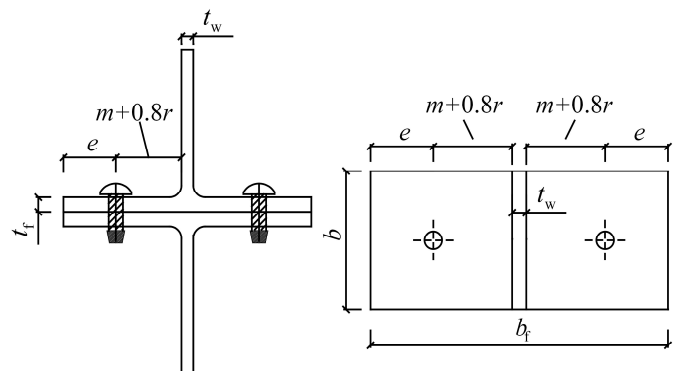

(a) TSS - T-stub with single row and single column of pins

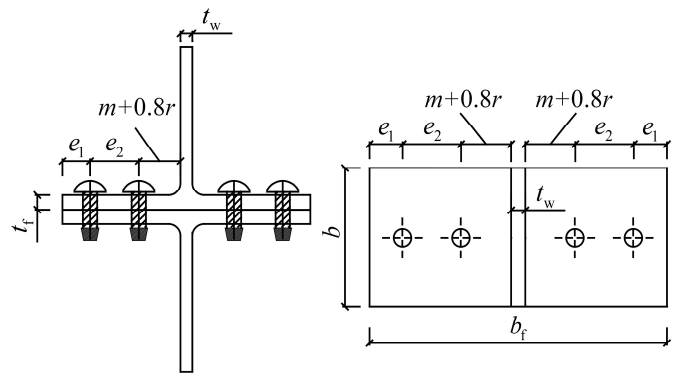

(c) TDS - T-stub with double rows and single column of pins

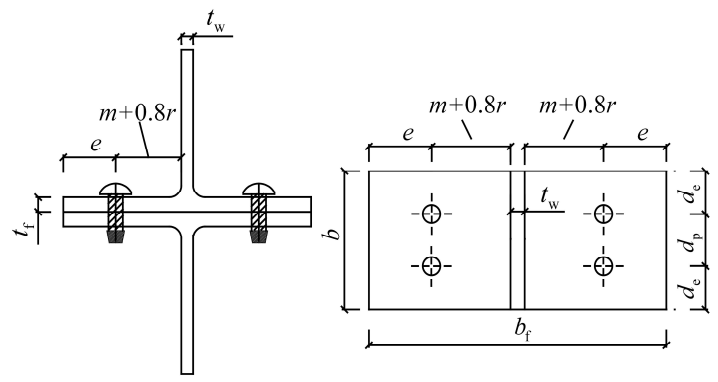

(b) TSD - T-stub with single row and double columns of pins

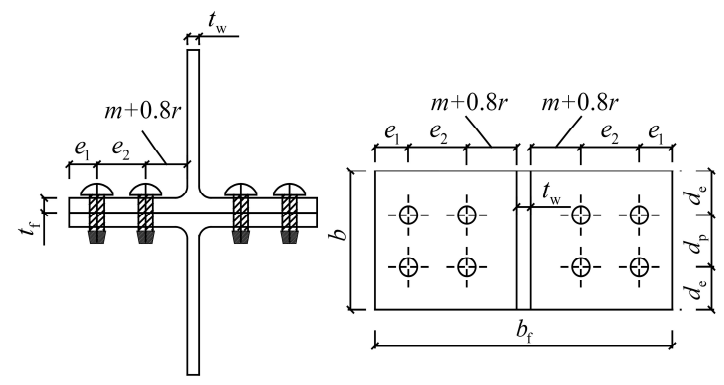

(d) TDD - T-stub with double rows and double columns of pins

Fig. 2. Details of aluminium alloy TSS, TSD, TDS and TDD T-stub test specimens

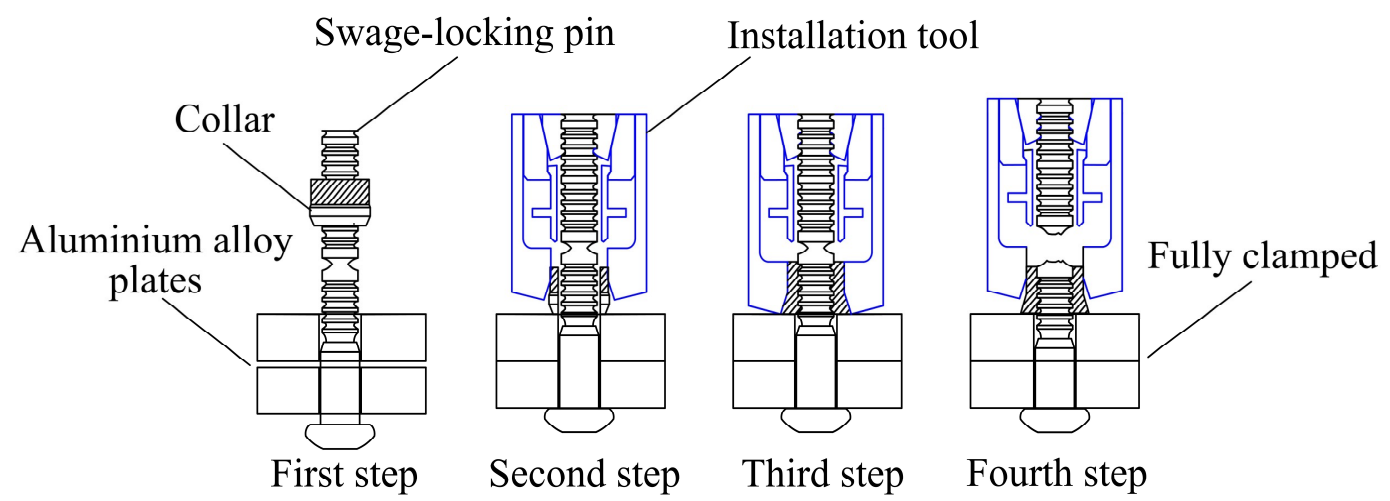

Fig. 3. Connecting process for swage-locking pins 

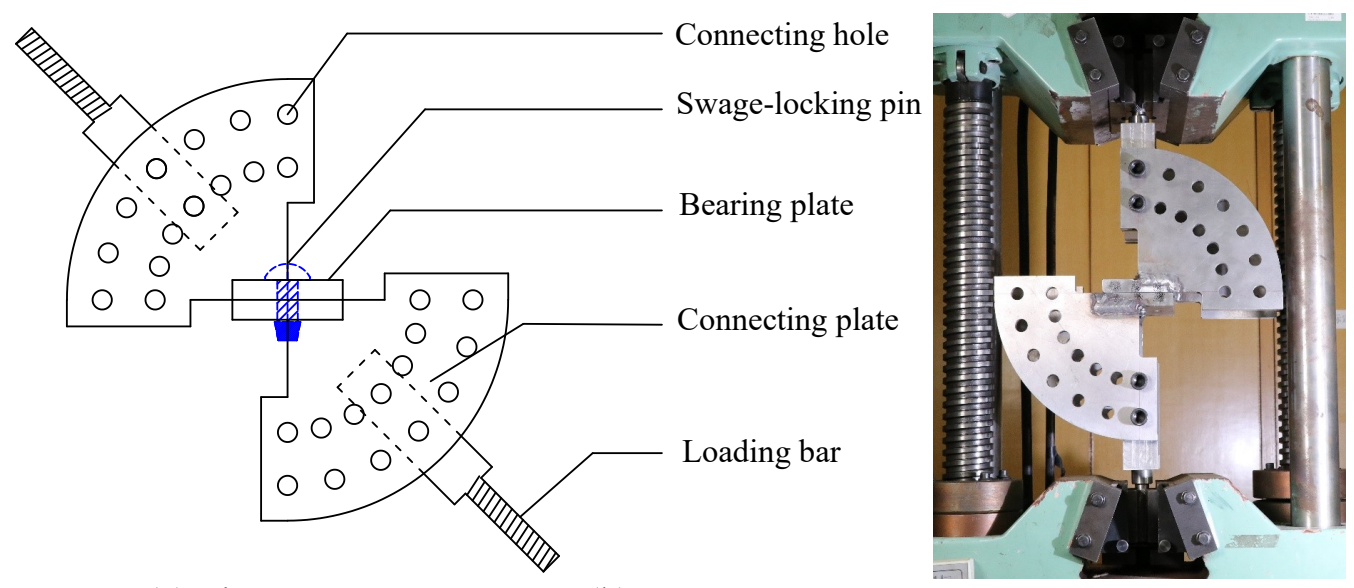

(a) Fixture

(b) Test setup

Fig. 4. Experimental setup for tests on swage-locking pins

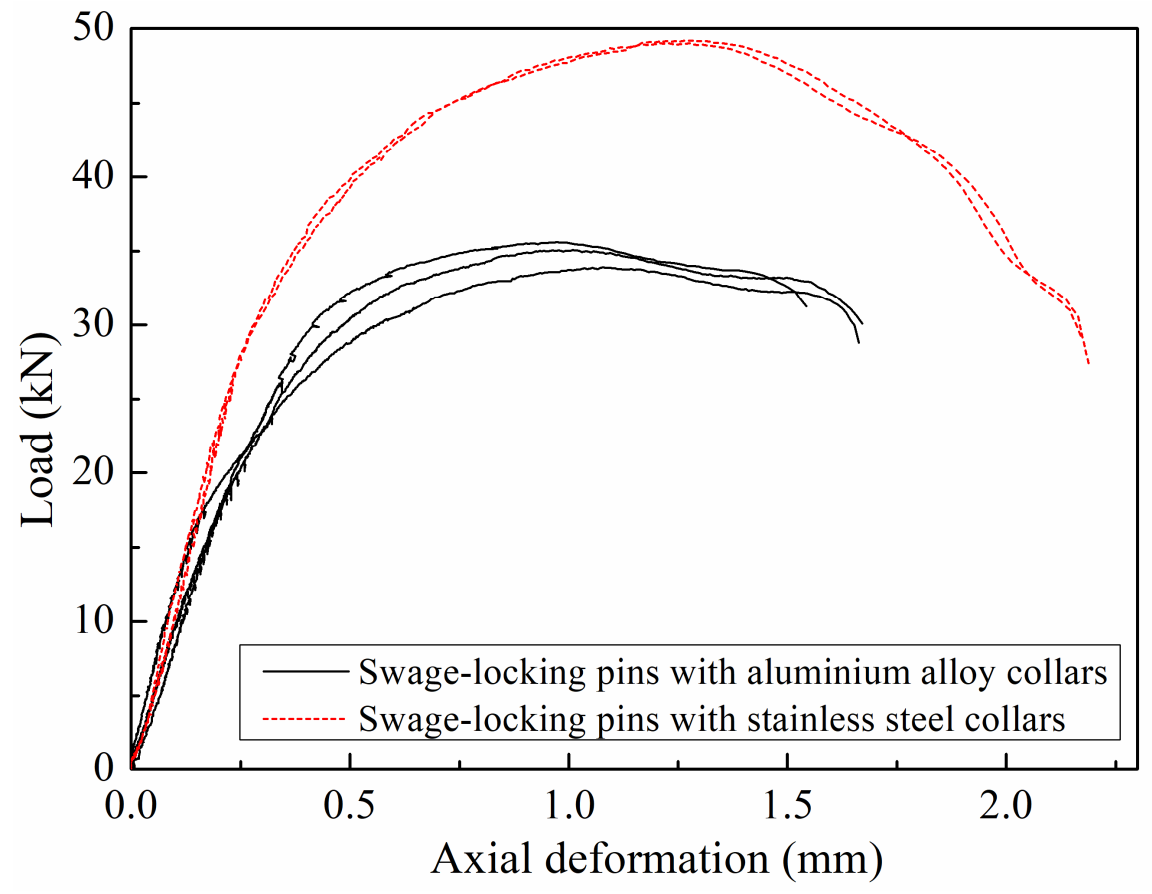

Fig. 5. Load-axial deformation responses of swage-locking pins under pure tension 
Aluminum alloy collar Stainless steel collar

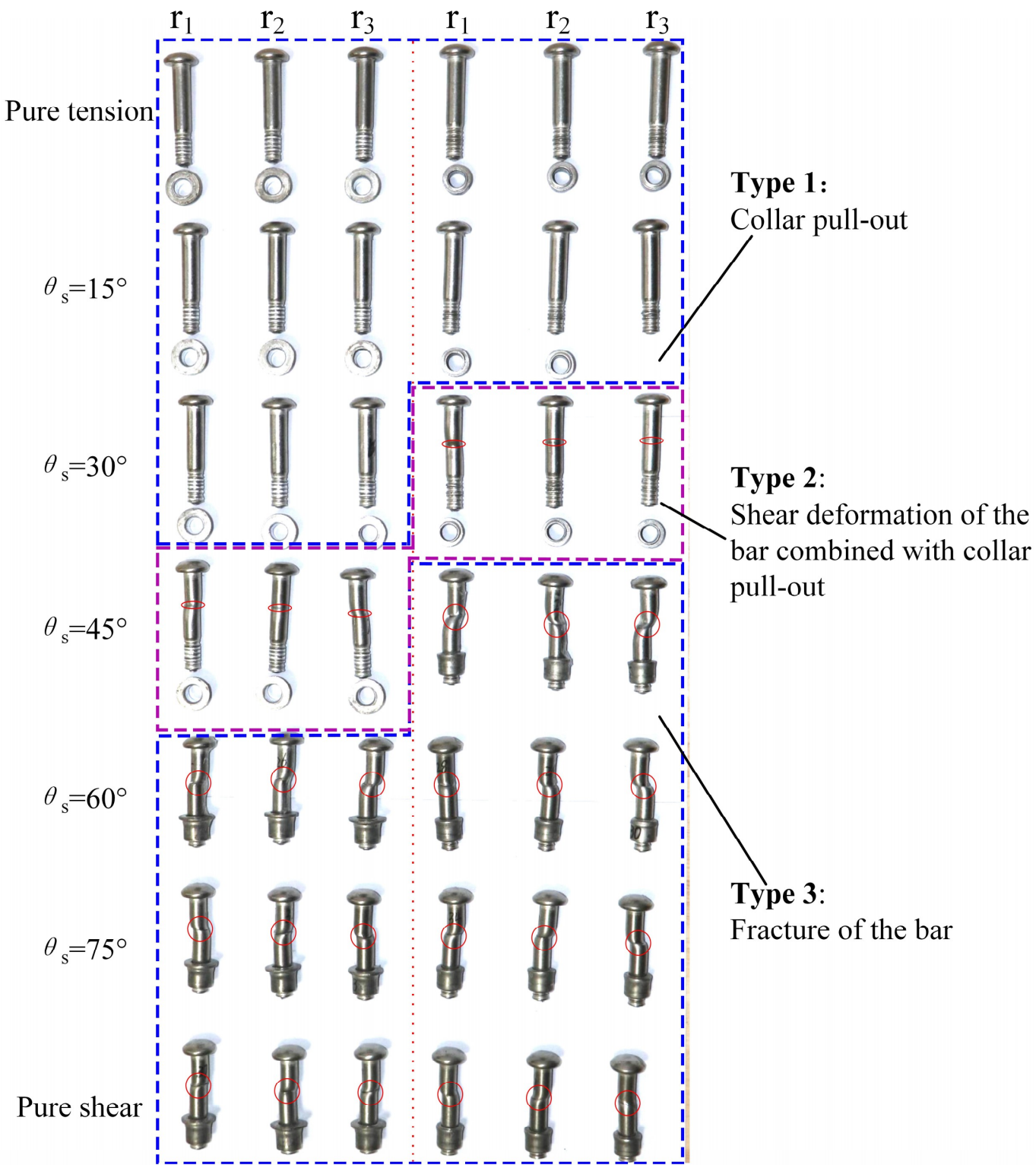

Fig. 6. Failure modes of all tested swage-locking pins 

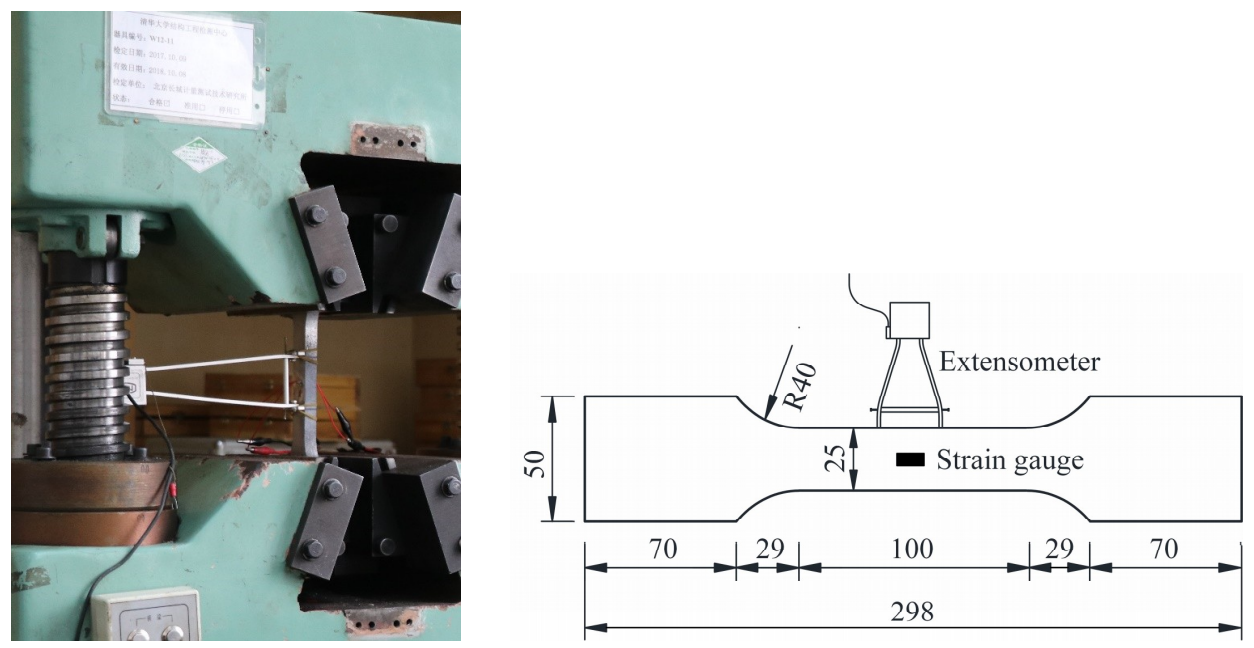

(a) Test set-up

(b) Dimensions of tensile coupon specimens (in $\mathrm{mm}$ )

Fig. 7. Test set-up and dimensions of flat tensile coupons extracted from T-stubs
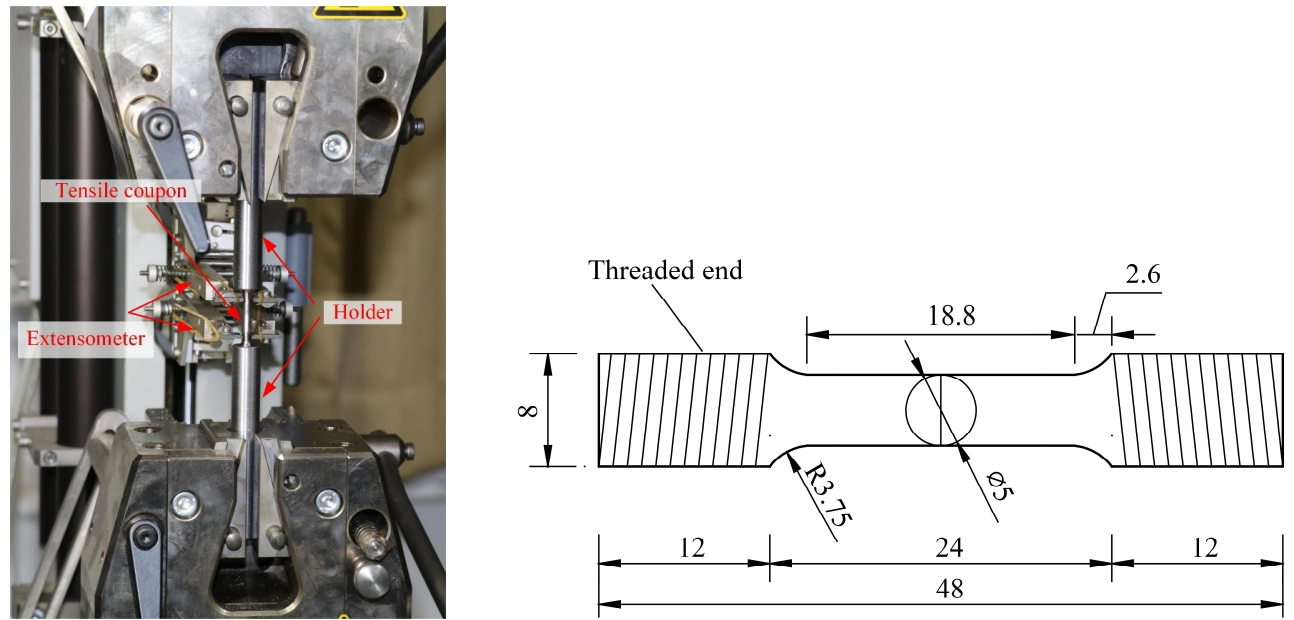

(a) Test set-up

(b) Dimensions of tensile coupon specimens (in $\mathrm{mm}$ )

Fig. 8. Test set-up and dimensions of round tensile coupons extracted from swage-locking pins 

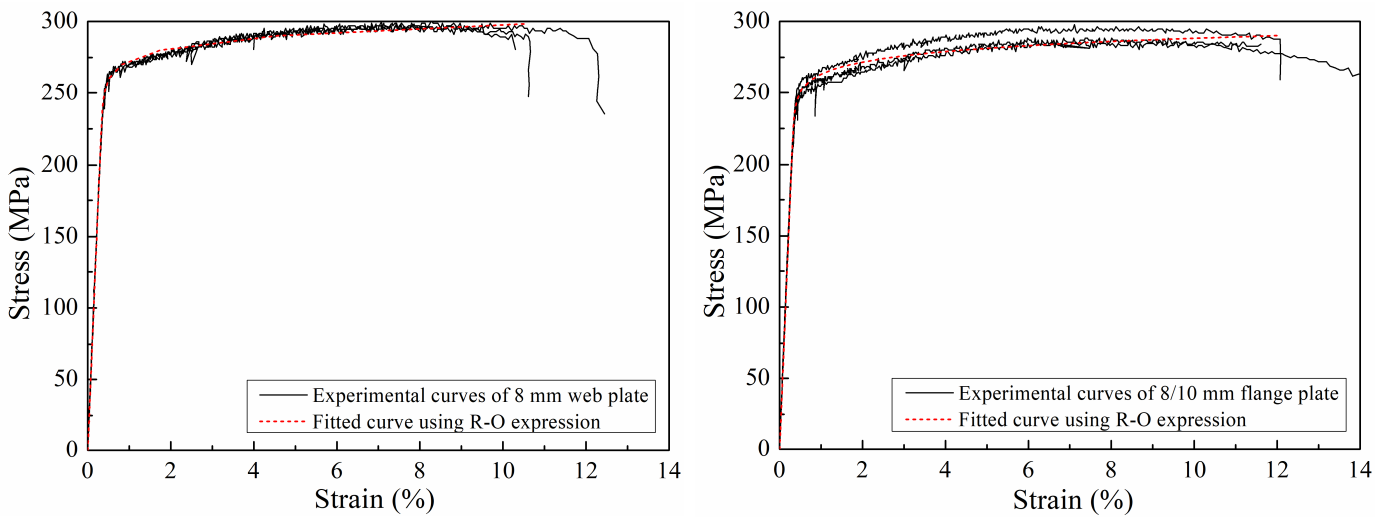

(a) $8 \mathrm{~mm}$ aluminium alloy web plate

(b) $8 / 10 \mathrm{~mm}$ aluminium alloy flange plate
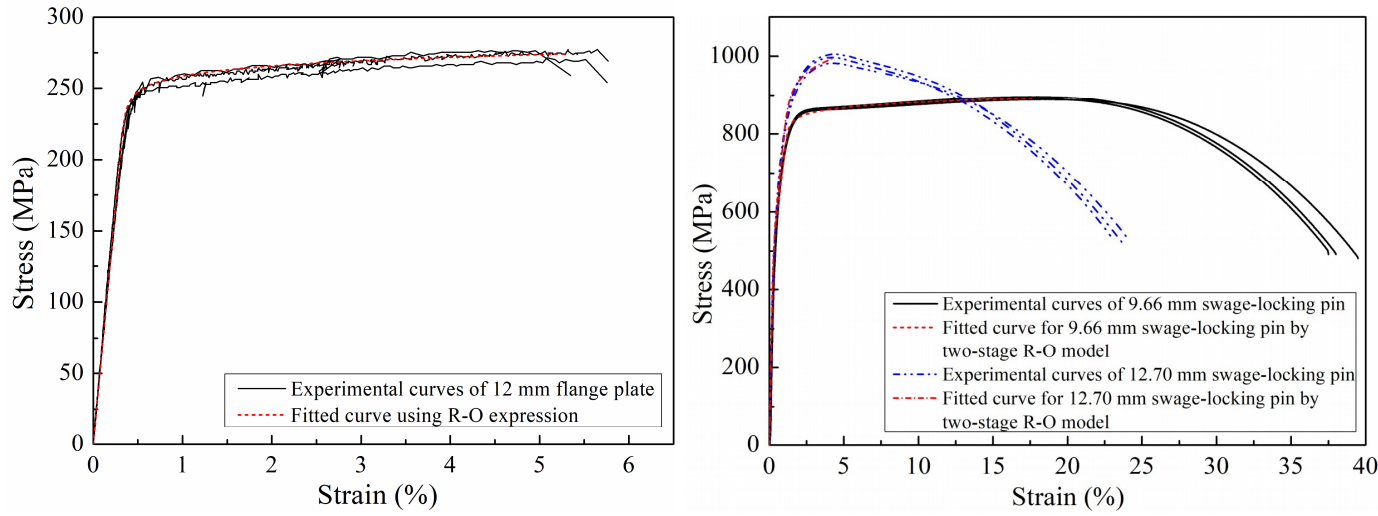

(c) $12 \mathrm{~mm}$ aluminium alloy flange plate

(d) Two types of swage-locking pins

Fig. 9. Stress-strain curves of aluminium alloy web and flange plates and swage-locking pins

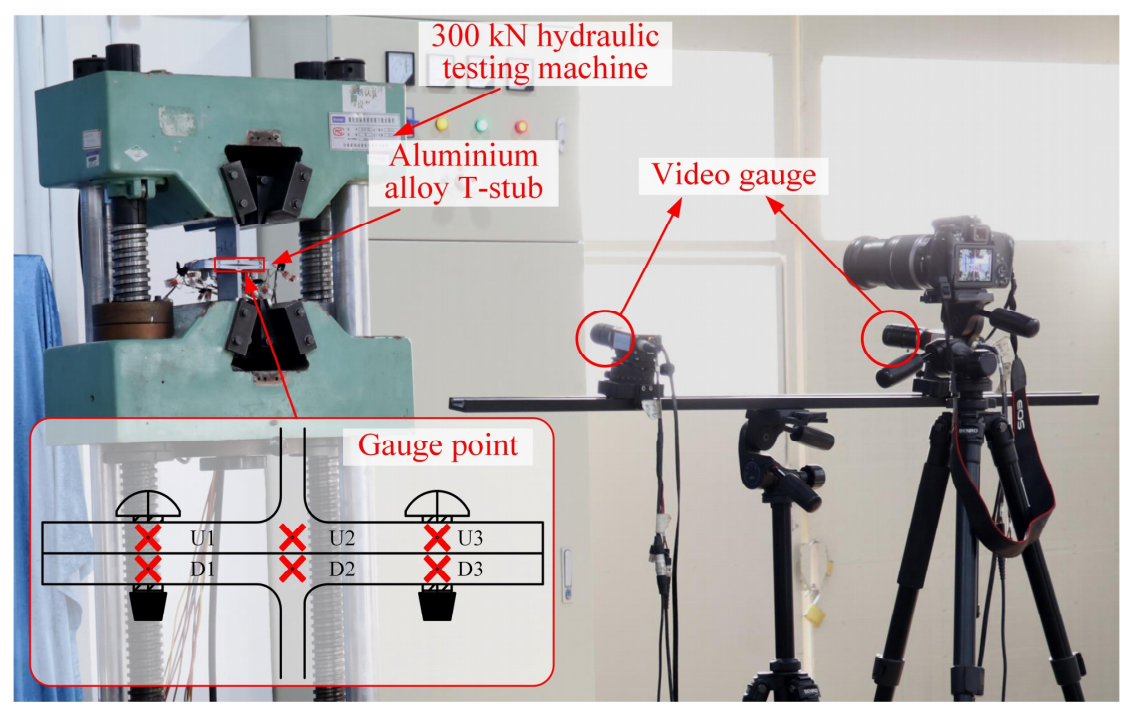

Fig. 10. Experimental set-up for T-stub tests 


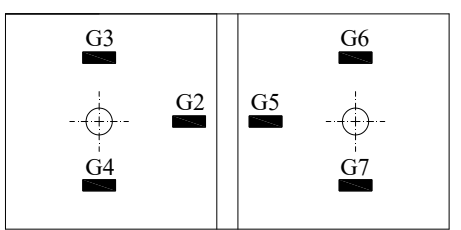

(a) TSS specimens

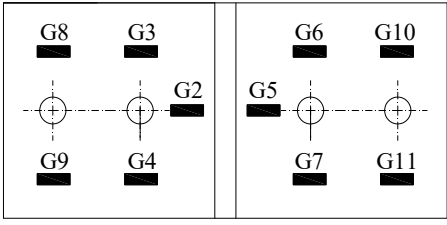

(c) TDS specimens

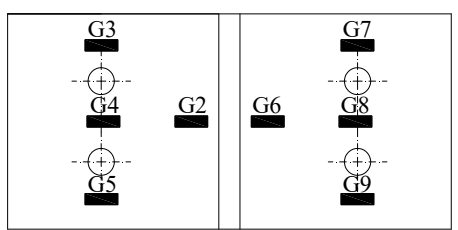

(b) TSD specimens

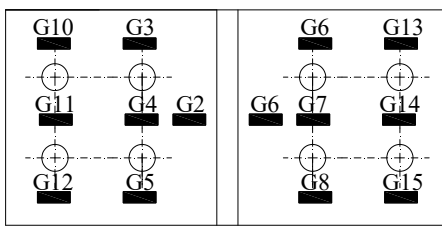

(d) TDD specimens

Fig. 11. Layout of strain gauges on T-stub test specimens
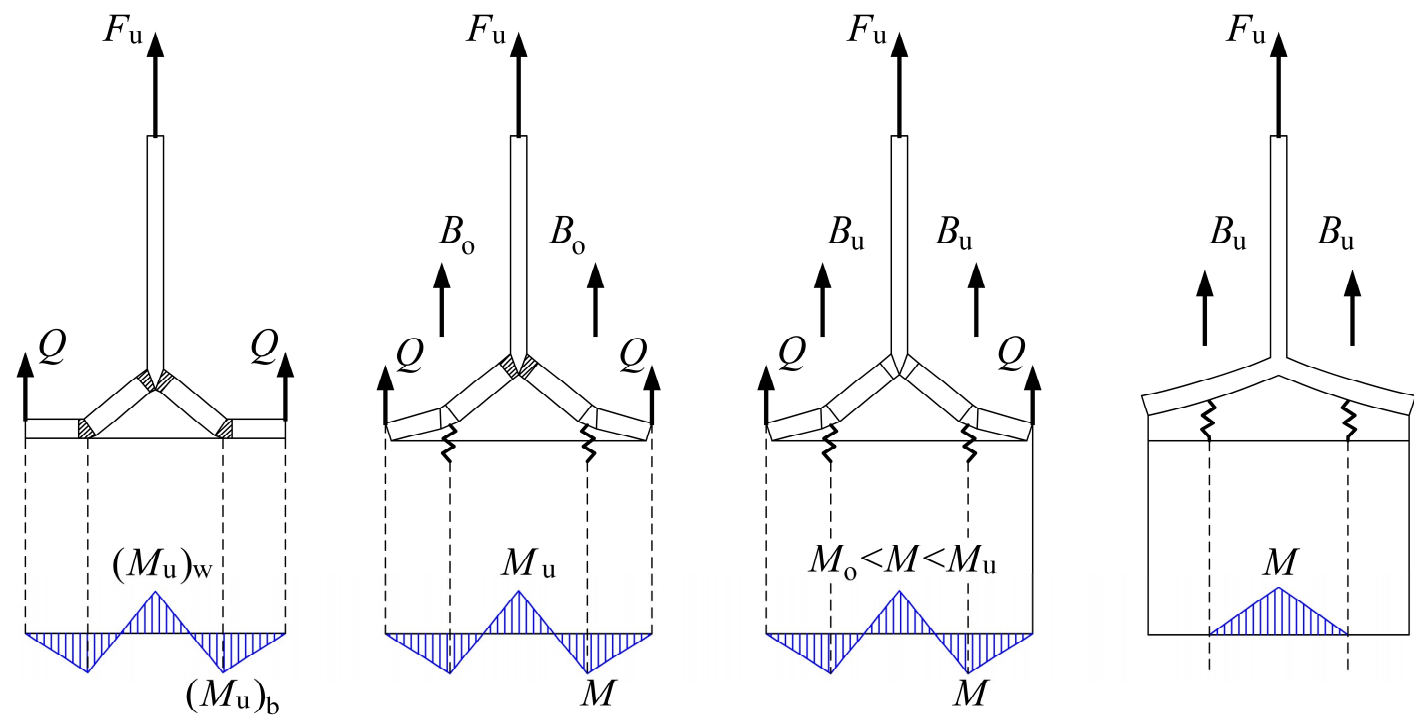

(1) Mode 1

(2) Mode 2a

(3) Mode 2b

(4) Mode 3

Fig. 12.Failure modes of aluminium alloy T-stubs according to EN 1999-1-1:2007

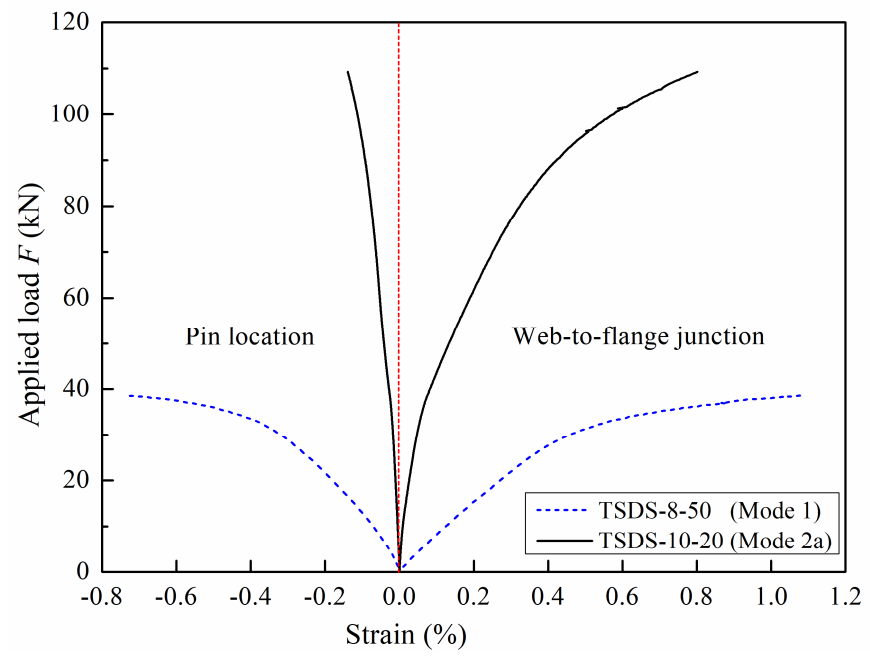

Fig. 13. Strain development at key locations in Specimens TSDS-8-50 and TSDS-10-20 

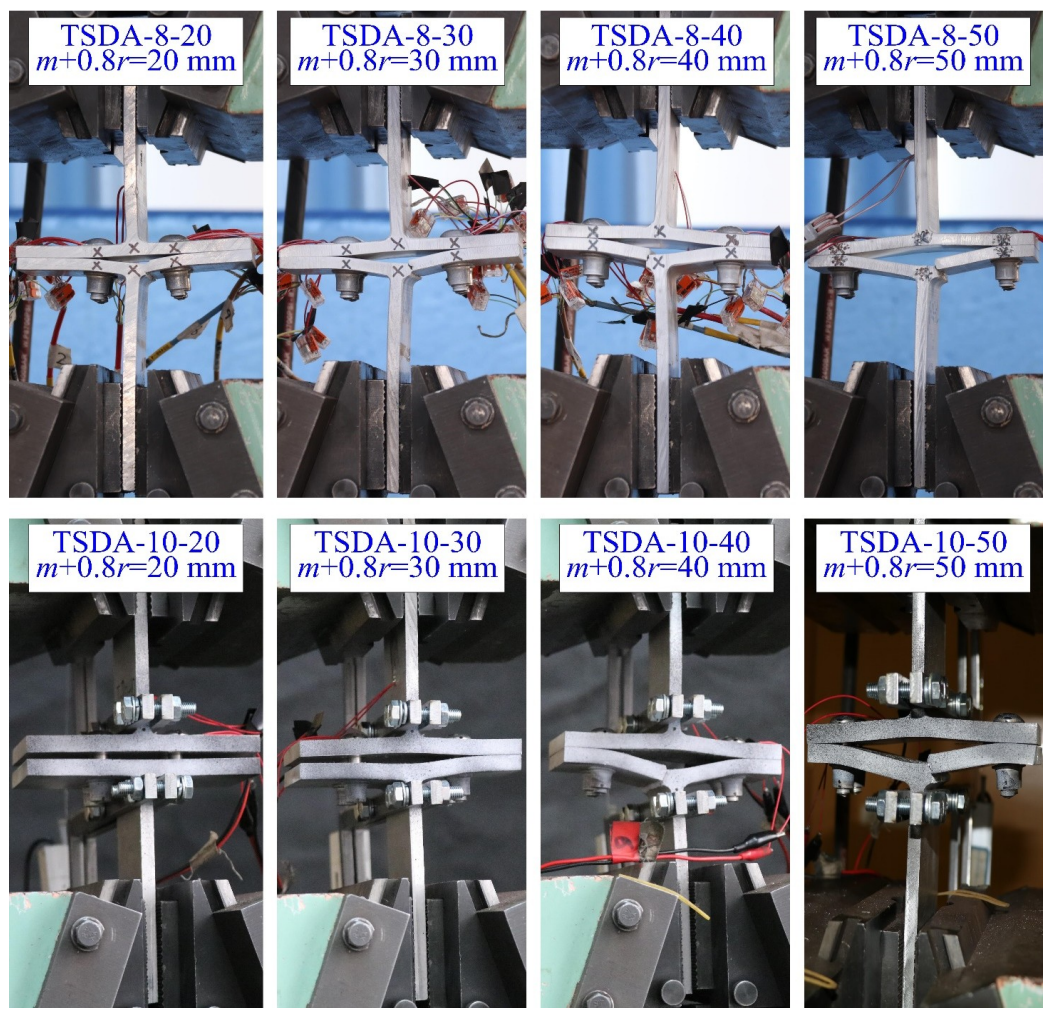

(a) Comparison of T-stub failure modes with varying distances between the pins and the web
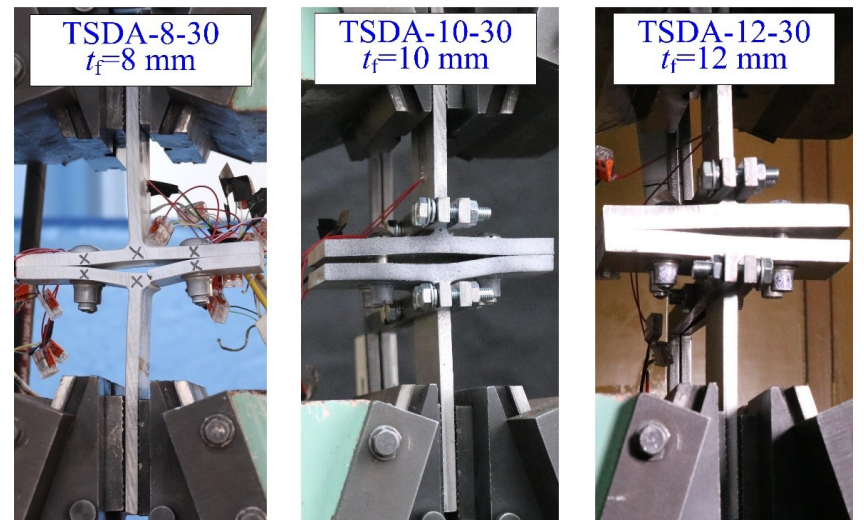

(b) Comparison of T-stub failure modes with varying flange thickness
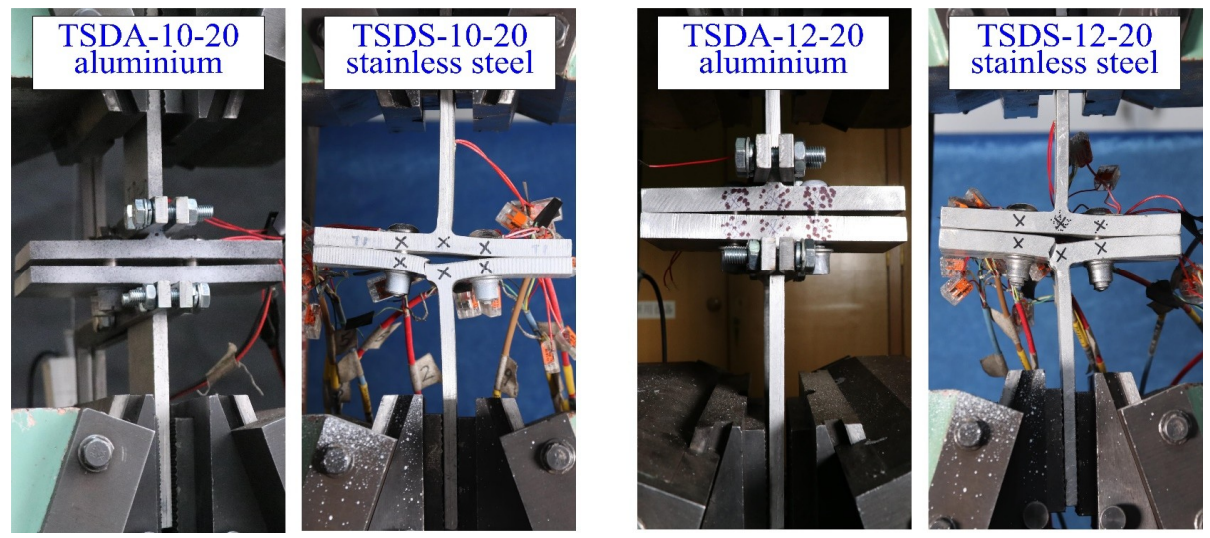

(c) Comparison of T-stub failure modes with different collar types 

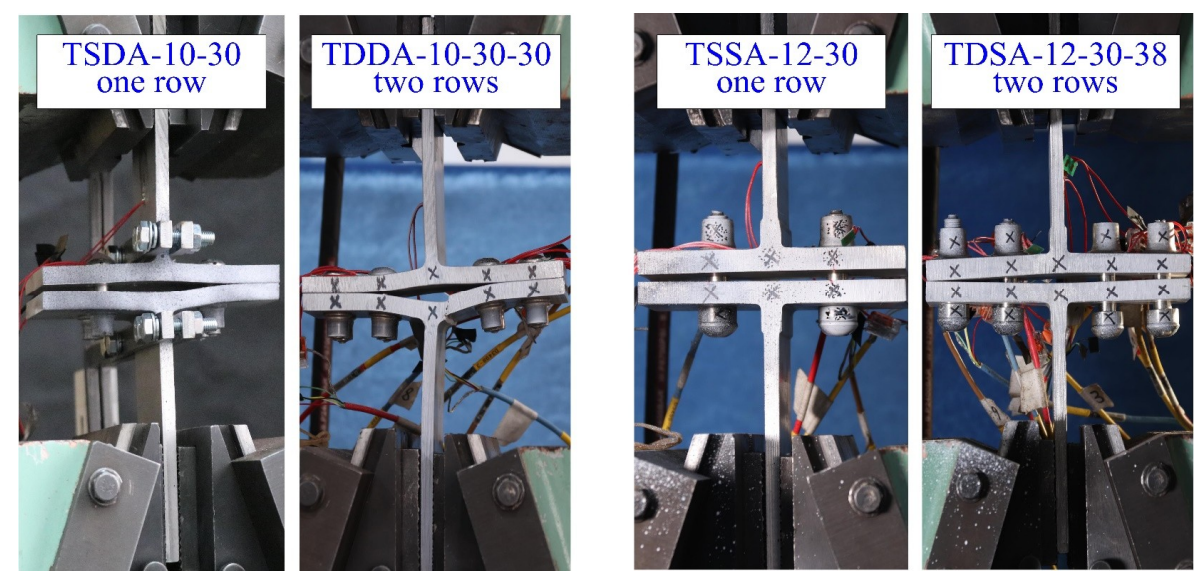

(d) Comparison of T-stub failure modes with varying numbers of rows of pins

Fig. 14. Comparison of experimental T-stub failure modes
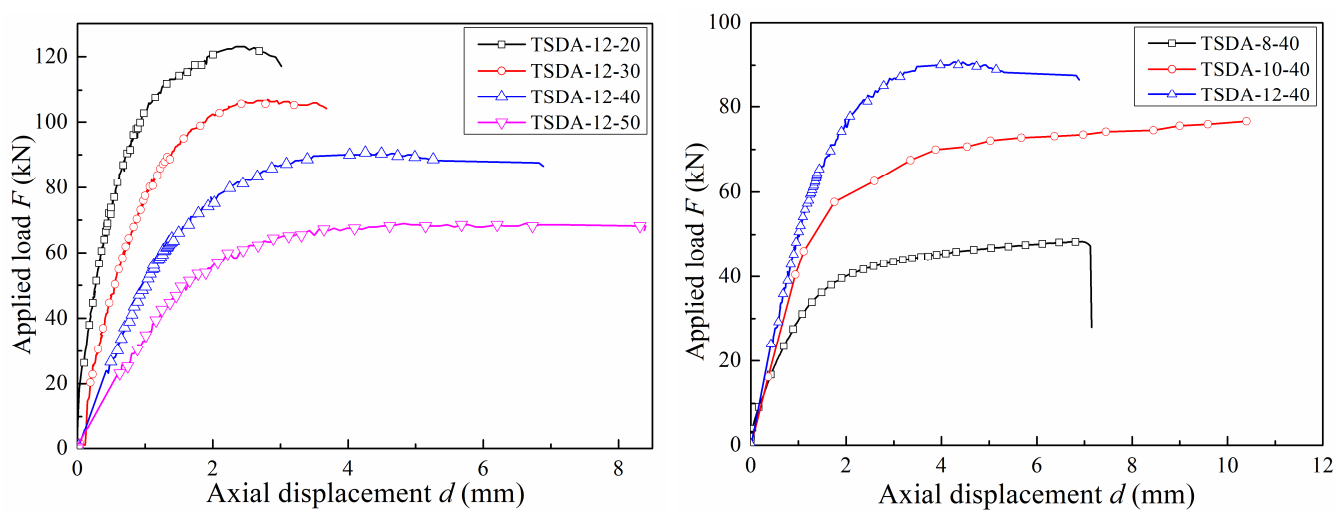

(a) Influence of distance between pins and web

(b) Influence of flange thickness
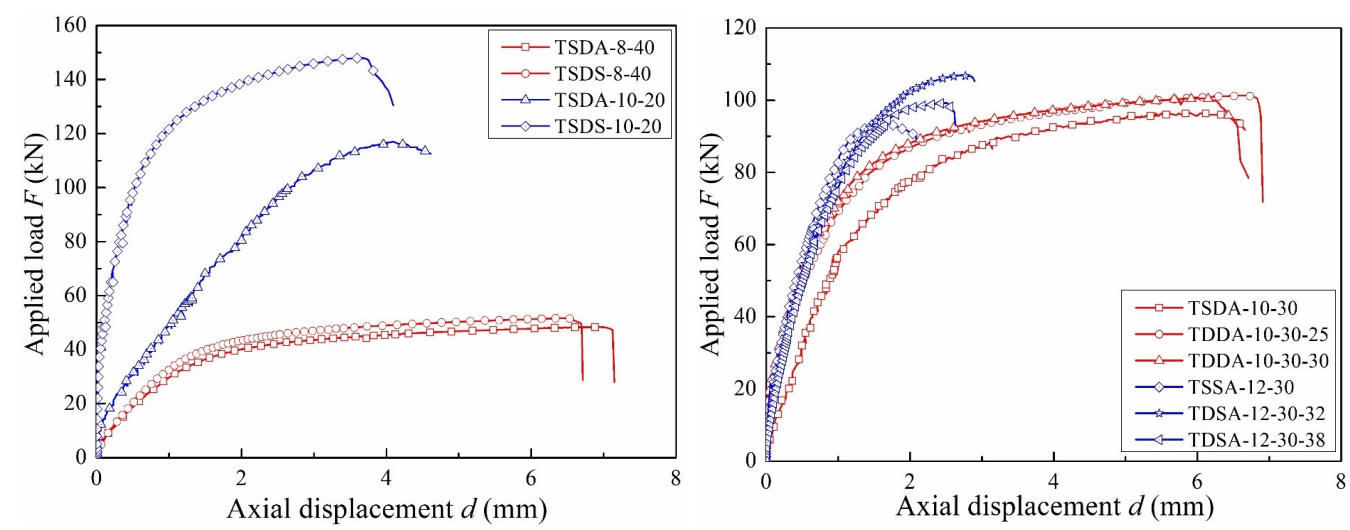

(c) Influence of collar type

(d) Influence of number of rows of pins

Fig. 15. Load-axial displacement curves of tested T-stubs 


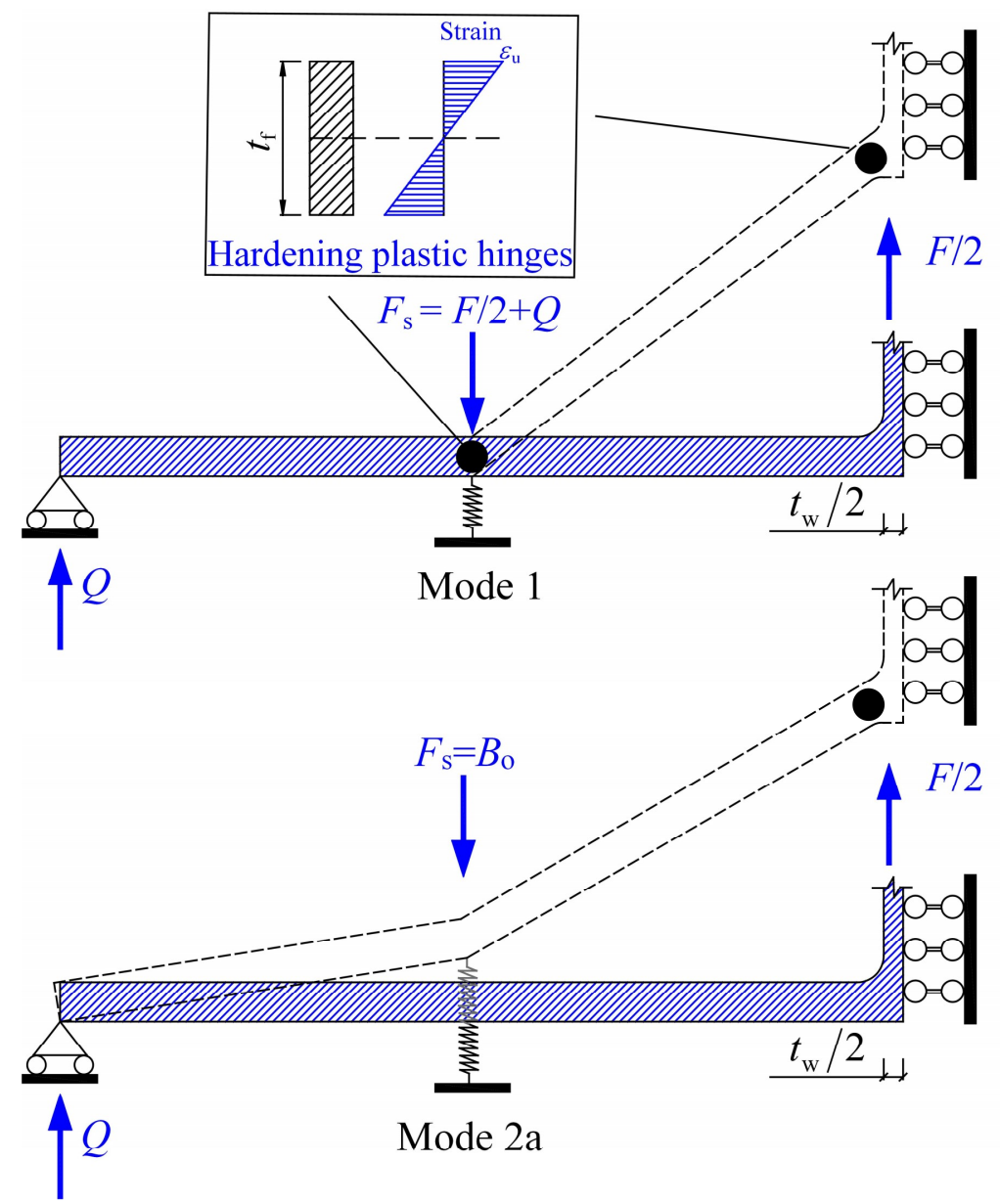

Fig. 16. Simplified models for Mode 1 and Mode 2a failure mechanisms of T-stubs featuring hardening plastic hinges

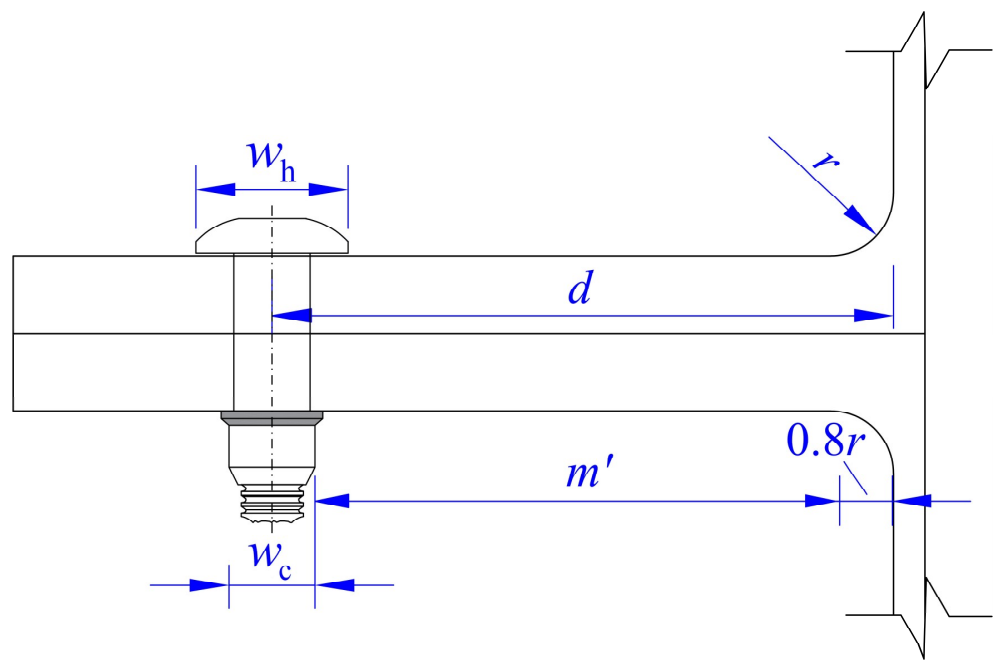

Fig. 17. Schematic diagram showing geometric dimensions of diameter of head of pin $w_{\mathrm{h}}$ and diameter of collar $w_{\mathrm{c}}$ 


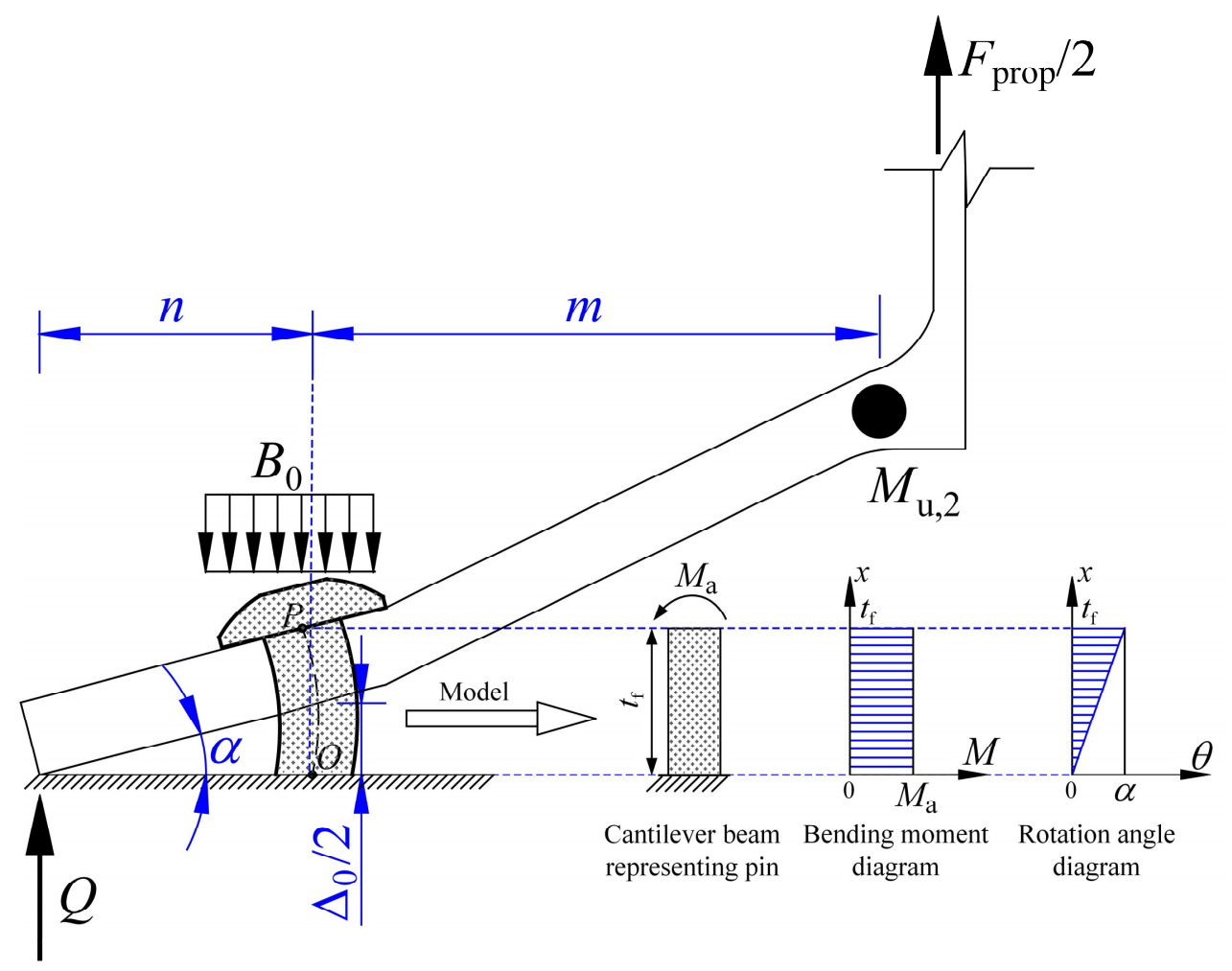

Fig. 18. Proposed analytical model for Mode 2a failure of T-stubs 